\title{
GUIDELINES
}

\section{Guidelines for the management of oesophageal and gastric cancer}

\author{
W H Allum, S M Griffin, A Watson, D Colin-Jones on behalf of the Association of \\ Upper Gastrointestinal Surgeons of Great Britain and Ireland, the British Society of \\ Gastroenterology, and the British Association of Surgical Oncology
}

Gut 2002;50(Suppl V):vl-v23

\section{INTRODUCTION}

These guidelines have developed as a joint project between the Association of Upper Gastrointestinal Surgeons of Great Britain and Ireland, the British Society of Gastroenterology, and the British Association of Surgical Oncology. They have been produced as part of the wider initiative of the British Society of Gastroenterology to provide guidance for clinicians in several areas of clinical practice related to the broad field of gastroenterology.

Over the past 10 years there have been many significant changes in the management of oesophageal and gastric cancer. Both diseases have shown remarkable changes in epidemiology with a concentration of tumours adjacent to the oesophagogastric junction. Advances in established investigative techniques and developments in new technology have radically altered the way in which the two diseases can be assessed without the need for surgery. Greater understanding of the natural history has significantly influenced the approach to diagnosis and to treatment options. Appreciation of the fundamental need for multidisciplinary treatment planning has reflected greater recognition by all interested clinicians of the role of the various treatment modalities. The essential role of best supportive care has significantly evolved emphasising the need for a holistic approach to all patients.

These guidelines have been written to emphasise these recent developments and to place them in the context of established approaches to enable clinicians to incorporate them into their clinical practice. They have not been written, nor are they intended, to be prescriptive, as such an approach would interfere with clinical judgement. However, they have been produced based on careful review of the available evidence with the recommendations weighted according to the strength of the evidence. As with other similar recommendations, much of the evidence is based on consensus view as in many areas scientific evaluation has not taken place or is not possible. Such limitations are inevitable in some areas of clinical practice. As a result, improvements will be appropriate but such improvements will only be possible once standards such as these have undergone appropriate assessment in prospective audit. These guidelines are thus an initial phase in an audit cycle and will need to be revised after a relatively short period of time.

\section{STRUCTURE OF GUIDELINES}

A systematic review of the relevant literature and collation of the available evidence was undertaken to produce the first draft of the guidelines. Individuals contributing to their section were invited to do so because of their knowledge and expertise in the field, often including a research programme. The literature searches were conducted by section coordinators and varied in their strategy and extent, but as a minimum included searching Medline, Embase recent review articles, and their references. A formal systematic appraisal of the quality of each research paper was not undertaken. This draft was amended to ensure an equivalent style. The editorial group (WHA, SMG, DC-J, AW) edited the individual sections and the final draft was submitted to independent expert review and modified appropriately. The strength of the evidence was classified according to the north of England evidence based guidelines development project. $^{1}$

\section{Categories of evidence}

Ia: Evidence obtained from meta-analysis of randomised controlled trials.

Ib: Evidence obtained from at least one randomised trial.

IIa: Evidence obtained from at least one well designed controlled study without randomisation.

IIb: Evidence obtained from at least one other type of well designed quasi-experimental study.

III: Evidence obtained from well designed descriptive studies such as comparative studies, correlative studies, and case studies.

IV: Evidence obtained from expert committee reports, or opinions or clinical experiences of respected authorities.

\section{Grading of recommendations}

Recommendations are based on the level of evidence presented in support and are graded accordingly.

Grade A requires at least one randomised controlled trial of good quality addressing the topic of recommendation.

Grade $B$ requires the availability of clinical studies without randomisation on the topic of recommendation.

Grade $C$ requires evidence from category IV in the absence of directly applicable clinical studies.

\section{SUMMARY OF RECOMMENDATIONS \\ Epidemiology and aetiology}

- There has been a marked increase in the incidence of adenocarcinoma of the lower third of the oesophagus and gastro-oesophageal junction in the past two decades with a corresponding decrease in incidence in distal gastric cancer (grade B).

- Oesophageal and gastric cancer rates may be decreased by measures to reduce smoking and alcohol intake and to increase dietary intake of fresh fruit and vegetables (grade C).

These guidelines have been prepared by the British Society of Gastroenterology. They represent a consensus of best practice based on the available evidence at the time of preparation. They may not apply in all situations and should be interpreted in the light of specific clinical situations and resource availability. 
- Oesophageal cancer may be influenced by a reduction in the duration and severity of gastro-oesophageal reflux and by a reduction in the incidence of obesity (grade $\mathrm{C}$ ).

- Eradication of Helicobacter may decrease gastric cancer incidence (grade C).

\section{Diagnosis}

- The index of suspicion for cancer is high when vague dyspeptic symptoms are combined with alarm symptoms (for example, weight loss, vomiting, and anaemia). General practitioners should be encouraged to refer patients as early as possible (grade B).

- Rapid access gastroscopy is the investigation of choice with appropriate biopsy for those with risk symptoms (grade C).

- Patients with a longstanding history of reflux and/or dysphagia should not be assumed to be suffering from benign stricture or simple oesophagitis until endoscopy and biopsy has been performed (grade C).

- High grade dysplasia of the oesophagus should precipitate urgent repeat endoscopy and biopsy as a significant number of patients will already have or develop intramucosal cancer (grade B).

- Antisecretory therapy should be ideally withheld until after endoscopy to avoid misdiagnosis (grade B).

- The diagnosis of gastric cancer should be suspected in all patients with recent onset "dyspepsia" over the age of 50 years (grade C).

- Gastric ulcers should be followed up to healing with repeat biopsy (grade B).

\section{Staging}

- Staging needs to be thorough and accurate for all patients in order to plan optimal therapeutic options (grade B).

- Accurate staging is achieved by a combination of techniques interpreted by dedicated staff in a timely fashion (grade B).

- Initial staging assessment should include spiral computed tomography (CT) of the thorax and abdomen to determine the presence or absence of metastatic disease (grade B).

- In the absence of metastatic disease, assessment of operability is preferably made by endoscopic ultrasound (grade B).

- Adjuncts to staging include magnetic resonance imaging (MRI), bronchoscopy, laparoscopy, and transabdominal ultrasound (grade B).

\section{Pathology}

- Diagnosis of high grade dysplasia both in Barrett's oesophagus and in the stomach should be made by an experienced histopathologist and corroborated by a pathologist with a special interest in gastrointestinal disease (grade C).

- Reports on oesophageal resection specimens should include, as a minimum, type of tumour, depth of invasion, involvement of the resection margins, vascular invasion, the presence of Barrett's metaplasia, and the number of nodes resected and the number containing metastatic tumour (grade B).

- Reports on gastric resection specimens should include, as a minimum, type of tumour, depth of invasion, involvement of the resection margins, nodal disease (including number of involved lymph nodes), and metastatic spread (grade B).

Abbreviations: $\mathrm{CT}$, computed tomography; MRI, magnetic resonance imaging; 5-FU, 5-fluorouracil; ECF, epirubicin, cisplatin, and 5-FU FAMTX, 5-FU, adriamycin, and methotrexate; PDT, photodynamic therapy; APC, argon plasma coagulation; ACA, adenocarcinoma; SCC, squamous cell carcinoma; EUS, endoscopic ultrasound; ASA, American Society of Anesthesiologists.
- Oesophagogastric junctional tumours should be classified as type I (distal oesophageal), type II (cardia), and type III (proximal stomach) (grade C).

\section{Treatment}

- Treatment and management of all patients should be undertaken in the context of a multidisciplinary team which plans and performs staging, treatment selection (radical and palliative), treatment provision, post-treatment care, and follow up (grade C).

- Careful evaluation of the patient's pretreatment health must be made, particular attention being paid to the cardiovascular and respiratory systems and performance status (grade C).

\section{Preoperative assessment}

- Routine investigations should include haematological and biochemical profiles (grade C), a resting ECG (grade B), chest $x$ ray (grade $\mathrm{B}$ ), pulmonary function tests (grade $\mathrm{B}$ ), and exercise testing (grade $\mathrm{C}$ ).

- Optimising the patient's fitness for surgery is a multidisciplinary process and all available expertise should be utilised (grade C).

- Patients should be encouraged to stop smoking immediately (grade C).

- All patients should have antithrombotic (grade A) and antibiotic prophylaxis (grade C) instituted at an appropriate time in relation to their surgery and postoperative recovery.

- Anaesthesia for oesophageal surgery should only be conducted by anaesthetists familiar with one lung ventilation and epidural analgesia (grade $\mathrm{C}$ ).

- Quality of life at presentation should be assessed and taken into consideration in treatment planning (grade B).

\section{Treatment: oesophageal resection}

- Oesophagectomy should be undertaken only in centres capable of carrying out careful case selection, with a large case volume and sufficient surgical and intensive care experience (grade $\mathrm{B}$ )

- There is no evidence favouring one method of oesophageal resection over another (grade C).

- The operative strategy should ensure that adequate longitudinal and radial resection margins are achieved whenever possible, along with a lymphadenectomy appropriate to the histological tumour type and its location (grade B).

- Single layer manual or stapled anastomoses can be used (grade B).

- Clinical anastomotic leakage should not exceed 5\% (grade B).

- Curative (R0) resection rates should exceed 30\% (grade B).

- Overall hospital mortality for oesophageal resection should be less than $10 \%$ (grade B).

Treatment: gastric resection

- The best results are likely to be produced by experienced surgeons operating in specialised units as part of a multidisciplinary team (grade B).

- Distal (antral) tumours should be treated by subtotal gastrectomy and proximal tumours by total gastrectomy (grade B).

- Limited gastric resections should presently only be used for palliation or in the very elderly (grade B).

- Patients with curable cancers of the stomach should undergo a D2 lymphadenectomy (grade B).

- The extent of lymphadenectomy should be tailored to the age and fitness of the patient together with the location and stage of the cancer (grade C).

- The distal pancreas and spleen should not be removed as part of a resection for a cancer in the distal two thirds of the stomach (grade A). 
- The distal pancreas should be removed only when there is direct invasion and still a chance of a curative procedure in patients with carcinoma of the proximal stomach (grade A).

- Resection of the spleen and splenic hilar nodes should only be considered in patients with tumours of the proximal stomach located on the greater curvature/posterior wall of the stomach close to the splenic hilum where the incidence of splenic hilar nodal involvement is likely to be high (grade C).

- Curative (R0) resection rates should exceed 30\% (grade B).

- Inhospital mortality should be less than $10 \%$ for total gastrectomy and less than 5\% for subtotal/partial gastrectomy (grade B).

\section{Treatment: chemotherapy and radiotherapy}

Oesophageal cancer

- There is no evidence for a role of adjuvant chemotherapy in oesophageal cancer (grade B).

- Neoadjuvant chemotherapy with cisplatin and 5-fluorouracil (5-FU) improves short term survival over surgery alone (grade B).

- There is no evidence to support the use of preoperative radiotherapy in oesophageal cancer (grade A).

- Preoperative chemoradiation may improve long term survival (grade B).

- Chemoradiation is the definitive treatment of choice for localised squamous cell carcinoma of the proximal oesophagus (grade $\mathrm{B}$ ).

\section{Gastric cancer}

- 5-FU is the most active chemotherapeutic agent. A combination of 5-FU with other agents is superior to single agent treatment. The combination of epirubicin, cisplatin, and continuous infusion of 5-FU (ECF) appears to be one of the most active regimens (grade B).

- Adjuvant chemotherapy/chemoradiotherapy are currently not standard practice for resected gastric cancer and should be offered only within the setting of a clinical trial (grade A).

- Intraperitoneal chemotherapy remains investigational (grade B).

- Neoadjuvant chemotherapy remains investigational with no definite evidence of survival benefit and clinical trials are continuing (grade B).

\section{Palliative treatment}

- Palliative treatment should be planned by the multidisciplinary team with direct involvement of the palliative care team and the clinical nurse specialist (grade C).

\section{Oesophageal cancer}

- Dilatation alone should be reserved for patients who are considered to have an extremely short life span (four weeks or less) and unable to swallow saliva, or as a very short term measure to relieve dysphagia while more definitive treatment is planned (grade B).

- Injection of tumour with $0.5-1 \mathrm{ml}$ aliquots of $100 \%$ alcohol should be considered in the following situations:

- (a) For eccentric or soft exophytic tumours, unsuitable for endoscopic intubation (grade B).

- (b) Tumours too close to the cricopharyngeus for endoscopic intubation (grade B).

- (c) For treatment of tumour overgrowth at the ends of an oesophageal prosthesis (grade B).

- Oesophageal intubation is the treatment of choice for firm stenosing tumours (capable of retaining an endoprosthesis), more than $2 \mathrm{~cm}$ from the cricopharyngeus, where rapid relief of dysphagia in a one stage procedure is desirable (grade B).
- Expandable metal stents are preferable to plastic tubes in view of the lower complication rate at insertion and shorter hospital stay (grade B).

- Covered expandable metal stents or cuffed plastic tubes are the treatment of choice for malignant tracheoesophageal fistulation or following oesophageal perforation sustained during dilatation of a malignant stricture (grade B).

- Laser treatment is effective for relief of dysphagia in exophytic tumours of the oesophagus and gastric cardia and in treating tumour overgrowth following intubation (grade A).

- For patients whose dysphagia is palliated using laser therapy, the effect can be prolonged substantially by using adjunctive external beam radiotherapy or brachytherapy (grade A).

- Chemoradiation provides a survival benefit over radiotherapy alone (grade B).

- Radiotherapy or chemotherapy alone palliate dysphagia more slowly than intubation or laser treatment (grade B).

- Both photodynamic therapy (PDT) and argon plasma coagulation (APC) are experimental and their use is not currently recommended (grade B); there may be a role for APC in treating tumour overgrowth of stents (grade C).

\section{Gastric cancer}

- Palliative chemotherapy for locally advanced and/or metastatic disease provides quality of life and survival benefit (grade A).

- Currently there is no indication to recommend second line chemotherapy. Its role should remain in the context of a clinical trial (grade B).

- Downstaging of locally advanced disease with chemotherapy is possible in individual cases, with anecdotal reports of prolonged survival following complete surgical resection. However, no randomised trials have been conducted to demonstrate a survival advantage from addition of surgery following palliative chemotherapy (grade C).

\section{Follow up}

- In the absence of randomised controlled trials, the most persuasive arguments for follow up are patient support and audit. Audit should be structured with particular reference to outcome measures and should be regarded as a routine part of the work of the multidisciplinary team (grade C).

- The development of a role for clinical nurse specialists in follow up should be actively pursued (grade C).

\section{EPIDEMIOLOGY AND AETIOLOGY \\ Oesophageal cancer}

Descriptive epidemiology

Recent UK data for the mid 1990s indicate that there are an estimated 7000 new diagnoses and 6700 deaths from oesophageal cancer each year. ${ }^{23}$ The overall age standardised incidence has increased over recent decades especially among adenocarcinomas (ACA) close to the gastro-oesophageal junction. Data from the Office for National Statistics shows that the incidence for men and women in England and Wales is 12.6 and 5.9 per 100000 , respectively. ${ }^{4}$ Oesophageal cancer is essentially a disease of older age, with two thirds of cases being diagnosed over 65 years of age. ${ }^{4}$ The aetiology of oesophageal cancer appears to be different for each histological subtype and independent of this for different geographical regions. The two major groups are squamous cell carcinoma (SCC) and ACA.

\section{Alcohol and smoking}

Case control studies suggest that, in the West, SCC is strongly related to smoking and alcohol consumption whereas in other parts of the world such as China the aetiology is more 
complex. ${ }^{5}$ In the USA the risk of both SCC and ACA is increased by both smoking and alcohol although the increase is much greater for SCC (odds ratio $16.9 \vee 3.4 ; 9.5 \vee 1.8$, respectively). ${ }^{6}$ In Europe, the Americas, South Africa, northeast China, and Hong Kong, case control studies have show a synergistic dose dependent effect of both smoking and alcohol consumption, ${ }^{7-10}$ the risks increasing substantially in those who both smoke and drink. Smokers of pipes, hand rolled, and high tar cigarettes have the highest risk among smokers.

\section{Dietary factors}

Diets lacking in vegetables, fruit, and dairy products, with low intakes of vitamins A, C, and riboflavin have been shown to predispose to oesophageal squamous cancer. ${ }^{11-13}$ Increased risk is also associated with consumption of pickled vegetables. ${ }^{14}$ Iron deficiency anaemia through the Paterson-Brown-Kelly syndrome is also associated with squamous carcinoma of the oesophagus. In the West, nutritional deficiency is less likely to be important in the aetiology of oesophageal cancer. ACA, perhaps through gastro-oesophageal reflux, appears strongly associated with obesity, one recent study reporting an odds ratio of 7.6 in patients with a raised body mass index. ${ }^{15}$

\section{Gastro-oesophageal reflux}

Gastro-oesophageal reflux is complicated by Barrett's oesophagus in $6-14 \%$ of patients. Case control studies have shown a twofold relative risk of developing ACA of the oesophagus with reflux oesophagitis, ${ }^{16}$ the risk increasing with duration of symptoms ${ }^{17}$ particularly in male caucasians. Recent evidence has shown that longstanding severe symptoms of reflux are associated with an increased risk of ACA, with an odds ratio of $44 .^{18}$

\section{Achalasia}

Achalasia predisposes to squamous carcinoma of the oesophagus. The apparent risk of cancer is highest in the first year following diagnosis, probably because prevalent cancers lead to dysphagia, prompting the initial diagnosis of achalasia. Subsequently there is a 16-fold increase in the risk of developing SCC. Patients with achalasia should be aware of the risk of oesophageal cancer. The role of endoscopic surveillance is uncertain. A population based study estimates that 406 endoscopies in males and 2220 in females would be required to detect one case of oesophageal cancer. ${ }^{19}$ Furthermore, there are no data to suggest that even these rates of detection would improve prognosis. However, the increased risk is a common feature of other studies and other factors including duration of symptoms and degree of food retention need to be evaluated to define high risk patients. ${ }^{2021}$

\section{Primary prevention}

Elimination of any aetiological factors from a population in order to try to minimise the chance of malignant transformation in the oesophagus cannot be fully achieved as the precise sequence of events involved in the development of oesophageal cancer has not been fully elucidated. Public health education programmes should encourage reduction in smoking and avoidance of excess alcohol intake. A diet rich in fruit and vegetables should be encouraged with up to five servings per day.

Reduction in gastro-oesophageal reflux may be achieved by suppressing gastric secretion pharmacologically or by surgery. It has not been convincingly demonstrated that such measures might reduce the risk of oesophageal ACA, although this is the subject of an international prospective randomised study in patients with Barrett's oesophagus.

\section{Gastric cancer}

Descriptive epidemiology

Gastric cancer remains a relatively common malignancy in the UK. Recent UK data for the mid 1990s indicate that there are an estimated 10000 new diagnoses and 7500 deaths from gastric cancer each year. ${ }^{2}$ The overall age standardised incidence has shown a steady decrease over the past few decades. However, this has had relatively little impact on the workload associated with gastric cancer, which has remained fairly constant, reflecting the ageing population. ${ }^{22}$ Data from the Office for National Statistics show that the incidence for men and women in England and Wales is 20.4 and 7.4 per 100000 , respectively. ${ }^{4}$ Gastric cancer is essentially a disease of older age, over $80 \%$ of cases being diagnosed after 65 years of age $^{4}$ although a regional survey suggested that early gastric cancer (disease limited to the mucosa and submucosa) generally affects a population approximately 10 years younger than more advanced disease. ${ }^{23}$ In the UK, as elsewhere, the incidence of gastric cancer is strongly associated with poor socioeconomic status and this largely explains the geographical pattern of disease, with higher rates in the north of England, Wales, and Scotland.

\section{Anatomical location}

There has been an intriguing change in the anatomical subsite distribution of gastric cancer, with a trend for tumours to be found more in the proximal stomach, particularly around the cardia, and a reduction in the incidence in the distal stomach. ${ }^{24-26}$ There has been an absolute increase in tumours in the cardia region and this has led to the suggestion that such cancers, along with ACA of the lower oesophagus, may be associated with gastro-oesophageal reflux. ${ }^{18}$

\section{Gastritis as an aetiological factor}

Chronic inflammation of the gastric mucosa can lead to intestinal metaplasia and gastric atrophy, which are believed to be important precursors for malignant transformation. ${ }^{27}$ Patients with pernicious anaemia and those who have had previous gastric resection for benign disease were the first examples of this association..$^{28}{ }^{29}$ In the last decade there has been increasing evidence for the role of Helicobacter pylori infection. This organism causes a persistent active gastritis which usually becomes chronic and may progress to atrophy. There is an increased risk of gastric cancer in $H$ pylori infected individuals which has been assessed as 2-6-fold ${ }^{30-32}$ Recent meta-analyses conclude that the risk is approximately $2.5^{33-35}$ although this is increased for non-cardia cancers and possibly by infection with specific pathogenic strains of the bacterium. ${ }^{32}$ The relationship between infection and cardia cancer is currently unclear but there is a suggestion that eradication of $\mathrm{H}$ pylori may increase the risk of cardia cancer.

\section{Dietary factors}

There is much evidence to suggest that diet plays an important role in the aetiology of gastric cancer. In particular, diets containing low levels of fresh fruit and vegetable consumption increase the risk of this disease. ${ }^{36}{ }^{37}$ Dietary antioxidants may be the critical components of fruit and vegetables that are of aetiological importance. For example, in Venezuela, Munoz and colleagues ${ }^{38}$ found a reduced incidence of intestinal metaplasia in populations given a diet enriched in carotene and vitamins $\mathrm{C}$ and $\mathrm{E}$. It is also worth noting that the vitamin $\mathrm{C}$ content of the gastric mucosa of $H$ pylori infected subjects is lower than that in healthy mucosa. ${ }^{39}$ A high level of salt consumption $^{40}$ and a diet heavily dependent on preserved foods have also been postulated as important risk factors. ${ }^{36}{ }^{37}$

\section{Smoking}

As with a number of malignancies, smoking has been associated with an increased risk of gastric cancer although the magnitude of the risk is not as large as that for lung cancer. ${ }^{41}$

Familial risk

Gastric cancer families have been identified and there is known to be a small (2-3-fold) elevated cancer risk imparted 
Table 1 Upper gastrointestinal cancers: guidelines for referral ${ }^{47}$

- Dysphagia

- Dyspepsia combined with one or more of these alarm symptoms: Weight loss Anaemia Anorexia

- Dyspepsia in a patient aged 55 years or more with at least one of the following "high risk" features: Onset of dyspepsia less than one year ago Continuous symptoms since onset

- Dyspepsia combined with at least one of the following known risk factors: Family history of upper gastrointestinal cancer in more than one first degree relative Barrett's oesophagus

Pernicious anaemia

Peptic ulcer surgery over 20 years ago

Known dysplasia

Atrophic gastritis

Intestinal metaplasia

- Jaundice

- Upper abdominal mass

to first degree relatives of gastric cancer patients. ${ }^{42}$ This is supported by the link of germline E-cadherin mutations to some familial gastric cancers. Although this is suggestive of an inherited factor, the familial risk could also represent exposure to the same environmental influences.

\section{Primary prevention}

A diet with high intakes of fruit and vegetables (at least five servings per day) and, thereby, a satisfactory intake of antioxidants is generally appropriate health advice and likely, although not as yet proven, to reduce the incidence of gastric cancer. The increased risk of gastric cancer associated with $H$ pylori infection inevitably encourages the concept of a screening and eradication programme. It is not known however whether the mucosal changes induced by longstanding $H$ pylori infection are reversible and whether eradication will therefore influence the development of cancer.

\section{DIAGNOSIS OF OESOPHAGEAL AND GASTRIC CANCER}

Symptomatic presentation is a poor predictor of pathology ${ }^{43} 44$ as "dyspepsia" is very common. ${ }^{45}$ Awareness of "at risk" individuals is essential to facilitate early referral for assessment. ${ }^{46}$ Recent guidance for symptomatic referral from the UK Department of Health ${ }^{47}$ has specified the "at risk" symptoms which a general practitioner should use to seek specialist help to aid earlier diagnosis (table 1). It is recommended that the specialist should see such patients within two weeks of the general practitioner deciding the patient might have cancer and making the referral.

These recommendations reflect a pragmatic approach for symptomatic patients. However, there are specific areas as described below where such guidance may be modified. There is little data to suggest that a referral within two weeks will improve outcome quantitatively. Gastric cancers confined to the mucosa and submucosa have a doubling time of 1.5-10 years whereas advanced cancer has a doubling time of between two months and one year. ${ }^{46}{ }^{48}$ Reducing symptomatic delay is unlikely to significantly alter prognosis for early disease but in more advanced disease a small proportion may be amenable to potentially curative surgery. Appropriate audit is required to determine if overall survival can be improved by this approach.

The principal method of diagnosis in upper gastrointestinal cancer is endoscopy. The advantages of endoscopy are that biopsies can be taken and small lesions evaluated more fully than is possible with radiological studies. ${ }^{49}$ Radiology alone will miss a high proportion of early oesophageal cancers ${ }^{50}$ and other pathology such as foreign body reactions can mimic neoplastic disease. ${ }^{51}$
However, there is very little evidence that any diagnostic procedure affects outcome. ${ }^{52}$ Most studies have concentrated on early referral and ease of access for symptomatic patients. Several observational studies infer that open access endoscopy results in more cases of early stage disease, particularly gastric cancer. ${ }^{53}$ Other observational studies qualify this finding by highlighting the fact that open access results are heavily influenced by referral bias and that the majority of cases of gastric cancer still present at a late stage. ${ }^{54}$

\section{Symptoms}

\section{Oesophageal cancer}

The principal symptom of carcinoma of the oesophagus is dysphagia. Observational studies show that cancer accounts for one quarter of all patients presenting with true dysphagia ${ }^{55}$ and as such all patients with this symptom should be referred urgently for endoscopy or barium studies.

The increase in the incidence of ACA reflects the predominance of gastro-oesophageal reflux disease. Estimates suggest that $4-9 \%$ of adults experience daily heartburn and up to $20 \%$ experience symptoms on a weekly basis. Early assessment of such patients should be considered prior to starting empirical treatment as approximately $60 \%$ of patients with malignant disease localised to the submucosa are symptomatic at presentation..$^{56}$ Lagergren and colleagues ${ }^{18}$ have estimated the risk of developing ACA of the oesophagus by scoring symptoms of heartburn and regurgitation (alone or in combination), timing of symptoms, particularly occurring at night, and frequency of symptoms. Among those with recurrent symptoms of reflux the odds ratio of developing cancer were 7.7 in comparison with those without symptoms. More frequent, more severe, and longer lasting symptoms of reflux were associated with a greater risk (odds ratio 44).

\section{Gastric cancer}

Early gastric cancer

Early gastric cancer is defined as ACA confined to the mucosa or submucosa, irrespective of lymph node invasion. Observational studies indicate that approximately $70 \%$ of patients with EGC have symptoms of uncomplicated dyspepsia ${ }^{57} 58$ and are not complicated by anaemia, dysphagia, or weight loss. ${ }^{59}$ Other studies have confirmed the benign nature of symptoms in early stage disease..$^{534}$ Clinical diagnosis is very inaccurate in distinguishing between organic and non-organic disease $^{6061}$ and therefore all "at risk" patients with dyspepsia should be considered for endoscopy even though the overall detection rate is only $1-2 \%{ }^{62}$

Advanced gastric cancer

The majority of patients present with advanced disease with alarm symptoms such as weight loss, vomiting, anorexia, 
abdominal pain, and anaemia. ${ }^{59}$ In the UK, delays in diagnosis occur as a result of failure to investigate "at risk" patients with upper gastrointestinal symptoms. ${ }^{46}$ Such patients often have a long history of dyspepsia prior to being referred. ${ }^{54}$ Treatment with antisecretory therapy may also delay diagnosis or result in a misdiagnosis on first endoscopy. ${ }^{54}{ }^{63}$ In particular, the ability of proton pump inhibitors to "heal" malignant ulcers has not been fully appreciated..$^{63}{ }^{64}$ Thus a diagnosis needs to be established before such agents are used in "at risk" patients.

\section{Diagnosis}

The diagnosis of oesophageal and gastric cancer should always be confirmed by fibreoptic video endoscopy although barium studies may have been used as the primary investigation. Rigid oesophagoscopy is no longer recommended as flexible endoscopy is safer and more cost effective. ${ }^{65}$ The specificity of barium studies versus primary endoscopy is $\operatorname{similar}^{49}$ but endoscopy allows for biopsy and cytology, which are essential for confirming the diagnosis. ${ }^{66}$

There are no randomised trials to show a benefit of endoscopy over barium studies but it has been suggested that increasing the ease of investigating late onset dyspepsia could increase the proportion of early gastric cancers to $26 \%{ }^{57}$ Similar figures have been reported from Leeds and attributed to open access endoscopy. ${ }^{53}$ Other observational studies qualify this finding by highlighting the fact that open access results are heavily influenced by referral bias and that the majority of cases of gastric cancer still present at a later stage. ${ }^{54}$

\section{Barrett's oesophagus and dysplasia}

The diagnosis of Barrett's oesophagus is based on a combination of visual appearance and standard biopsy specimens. Before the recognition of short and ultrashort Barrett's oesophagus, it was possible to make the diagnosis on the observation of more than $3 \mathrm{~cm}$ of gastric metaplasia above the gastro-oesophageal junction. Shorter segment specialised columnar epithelium is defined as intestinal metaplasia in a columnar lined segment less than $3 \mathrm{~cm}$ in length. Intestinal metaplasia at the cardia, which is only detectable histologically, has been referred to as "ultrashort" segment Barrett's although its malignant risk is lower as it is more likely to be associated with $H$ pylori than gastro-oesophageal reflux disease.

The key point for the endoscopist is thus to be able to recognise which area to biopsy. The European Society of Gastrointestinal Endoscopy has recently published minimum standard terminology in digestive endoscopy. ${ }^{67}$ The length of Barrett's oesophagus has been defined as the distance between the transition from oesophageal mucosa to gastric mucosa (Z-line) and the upper end of the gastric folds, the position of the Z-line being recorded in centimetres from the incisors. Thus biopsies of this area are all important in confirming the diagnosis.

High grade dysplasia warrants urgent review of endoscopy with repeat biopsy and, if confirmed, careful consideration should be given to resection as in such patients re-evaluation will demonstrate malignant change in up to $40 \%$.

Areas of high grade dysplasia and microscopic ACA can be detected by multiple four quadrant biopsies of the oesophagus at $2 \mathrm{~cm}$ intervals throughout its entire length. ${ }^{68}$ Sampling can also be improved by taking "jumbo" biopsies of the oesophageal mucosa ${ }^{69}$ but even this technique may miss unsuspected Barrett's cancers. ${ }^{70}$

The role of surveillance endoscopy in patients with established Barrett's is controversial. Oesophageal cancers arising in Barrett's detected by surveillance are often early and have an excellent prognosis. However, studies have reported large numbers of endoscopies with little effect on diagnosis and overall survival. ${ }^{71}$ It remains to be established if those with risk factors such as ethnic origin, long segment metaplasia, male sex, smokers, and high alcohol intake are a more appropriate group for surveillance (cf British Society of Gastroenterology Guidelines on Barrett's oesophagus)

\section{Biopsy}

An endoscopic diagnosis of malignancy must be confirmed pathologically. Histology is the preferred method and the accuracy of diagnosis increases with the number of biopsies taken. ${ }^{72}$ Cytology can be used to complement histology but there is no evidence to show that cytology is better than biopsy alone. Indeed as in oesophageal cancer, a positive cytology result alone is insufficient evidence to proceed to definitive treatment for gastric cancer.

\section{Preoperative staging}

Aim

Accurate staging of gastro-oesophageal tumours is essential to allow a well informed decision to plan appropriate treatment (table 2). ${ }^{73}$ Advances in non-surgical management of advanced tumours demand accurate staging. Such precise stage dependent management will limit the incidence of unnecessary exploratory surgical interventions. Accurate tumour staging is also clearly important when comparing outcomes of various non-surgical interventions as there is no pathological "gold standard". At the other end of the disease spectrum there is also a requirement for accurate local tumour staging: small superficial early oesophagogastric cancers can sometimes be removed endoscopically but knowledge of the precise depth of tumour penetration and exclusion of more distant spread are essential prerequisites. Preoperative investigations that do not influence management decisions should be avoided.

\section{Methods}

Modalities for staging of oesophageal and gastric cancer should include spiral computed tomography (CT) and endoscopic ultrasound (EUS). Modalities and techniques that should be available for use in selected cases include chest radiography, trans-abdominal ultrasound, magnetic resonance imaging (MRI), bronchoscopy, and laparoscopy.

\section{Computed tomography}

Spiral contrast enhanced scans with thin collimation $(5 \mathrm{~mm})$ is optimal. Tumours at the cardia and within the stomach are best demonstrated following gastric distension with 600-800 $\mathrm{ml}$ of water. Distal body and antral tumours are best evaluated in the prone position.

\section{$T$ staging of the oesophagus}

CT cannot delineate the component layers of the oesophageal wall and therefore is unable to differentiate between $\mathrm{Tl}$ and $\mathrm{T} 2$ lesions. CT cannot detect microscopic invasion in T3 tumours and differentiating macroscopic $\mathrm{T} 3$ from focal tumour bulging or juxtalesional lymphadenopathy can be impossible, particularly in cachectic individuals. ${ }^{74}$ Understaging is more common than over staging. CT findings suggesting T4 involvement of the aorta, tracheobronchial tree, and crura are well documented but the signs are "soft" leading to poor sensitivity when compared with EUS. However, CT can predict mediastinal invasion in over $80 \%$ of patients. ${ }^{75-79}$

\section{T staging of the stomach}

Adequate gastric distension is required for CT to identify the primary lesion and determine the extent of the abnormal wall thickness. Achieving this distension can be problematic in patients with advanced gastric carcinoma.

CT cannot differentiate between $\mathrm{T} 1$ and $\mathrm{T} 2$ lesions. T3 lesions can be suggested by identifying stranding into the adjacent perigastric fat but differentiating between transmural extension and perigastric lymphadenopathy can be difficult. Most contemporary studies report accuracy of $80-88 \%$ 
Table 2 TNM classification of oesophageal and gastric cancer ${ }^{73}$

\begin{tabular}{|c|c|c|}
\hline Classification & Oesophagus & Gastric \\
\hline $\mathrm{T} 1$ & Lamina propria, submucosa & Lamina propria, submucosa \\
\hline $\mathrm{T} 2$ & Muscularis propria & Muscularis propria, subserosa \\
\hline T3 & Adventitia & Penetrates serosa \\
\hline $\mathrm{T} 4$ & Adjacent structures & Adjacent structures \\
\hline N1 & Regional nodes & $1-6$ nodes \\
\hline N2 & & $7-15$ nodes \\
\hline N3 & & $>15$ nodes \\
\hline M1 & Distant metastasis & Distant metastasis \\
\hline \multicolumn{3}{|c|}{ Tumours of lower oesophagus } \\
\hline Mla & Coeliac nodes & \\
\hline MIb & Other distant metastasis & \\
\hline \multicolumn{3}{|c|}{ Tumours of mid thoracic oesophagus } \\
\hline MIb & $\begin{array}{l}\text { Distant metastasis including non-regional } \\
\text { lymph nodes }\end{array}$ & \\
\hline \multicolumn{3}{|c|}{ Tumours of upper thoracic oesophagus } \\
\hline Mla & Cervical nodes & \\
\hline MIb & Other distant metastasis & \\
\hline
\end{tabular}

in identification of patients with advanced disease. ${ }^{80-82} \mathrm{~T} 4$ diagnosis on CT relies on the presence of contact between tumour and contiguous organs, a focal loss of intervening fat plane, or clear CT evidence of direct organ invasion. These signs may be difficult to evaluate in the cachectic patient. ${ }^{83} 84$

\section{Endoscopic ultrasound Oesophagus}

The ability to identify the component layers of the bowel wall provides the basis for tumour staging. EUS is superior to CT for local staging of oesophageal tumours ${ }^{76}{ }^{86}$ and is more accurate in predicting resectability although the complementary nature of these imaging techniques must be emphasised. ${ }^{878}$ Non-traversable stenotic oesophageal tumours at initial endoscopy require dilatation, preferably under image intensification. Such tumours are highly likely to be stage T3 or greater. ${ }^{89}$ The $8.5 \mathrm{~mm}$ "blind oesophagoprobe" passed over a guidewire is useful in stenotic tumours ${ }^{90}$ and technological improvements have overcome limitations related to the assessment of the depth of penetration.

\section{Stomach}

EUS is superior to CT for the local staging of gastric carcinoma $^{91}$ although the complementary nature of these imaging techniques must be emphasised. Higher frequency transducers can evaluate the subgroups of $\mathrm{Tl}$ and assess the suitability for endoscopic mucosal resection. The presence of direct invasion into adjacent structures (T4) can be assessed on EUS by demonstrating fixity.

A potential pitfall in staging is tumour penetration through the muscularis propria extending into the greater or lesser omenta but without penetration of the overlying visceral peritoneum. The TNM classification ${ }^{73}$ defines this as T2. However, the omental reflections around the stomach are not clearly seen with EUS and this classification raises important issues for EUS staging of gastric carcinomas. It is difficult or impossible to know if a carcinoma has penetrated the muscularis propria into the greater or lesser omenta but not breached the visceral peritoneum beyond-that is, ?T2 or ?T3. As in the oesophagus, there are a smaller but significant number of non-traversable stenotic tumours that prevent a full EUS evaluation $^{92}$

\section{$\mathrm{N}$ staging}

CT scanning

Size is the only criterion for assessment of lymph nodes and is a poor predictor of involvement, particularly in the chest, where large nodes may be reactive. The accuracy of CT diagnosis of mediastinal node involvement ranges from 38\% to $70 \%$. If nodes over $8 \mathrm{~mm}$ in diameter are considered abnormal in the coeliac axis, a sensitivity of $48 \%$ and a specificity of $93 \%$ is achieved.$^{77}$ Identification of more distant nodal groups is of particular importance as these nodal groups may not be amenable to evaluation with EUS and will often be outside the borders of even a radical resection.

The revised TNM classification has changed the classification of nodal involvement in gastric cancer. Previous classifications emphasised the importance of the distance of the involved nodes from the primary tumour. However, the current classification places emphasis on the number of involved nodes. Stage N1 refers to metastases in 1-6 regional nodes, N2 7-15 nodes, and N3 involvement of more than 15 nodes. All published papers addressing the accuracy of EUS and CT in the staging of gastric cancer utilise the "old" TNM classification. The impact of these changes on the accuracy of current imaging modalities remains to be seen.

\section{Endoscopic ultrasound}

Lymph nodes are well seen and certain features have been shown to correlate well with malignant infiltration. Nodes with well defined margins greater than $1 \mathrm{~cm}$ in diameter, rounded, and hypoechoic are likely to be involved.9. ${ }^{93}$ Malignant nodes unfortunately may not demonstrate all four features, and large benign reactive nodes are well recognised. EUS guided fine needle node aspiration cytology may be helpful $^{94} 95$ although the limitations of a negative result must be understood. Involved coeliac axis lymph nodes suggesting Mla disease from an oesophageal primary can be readily identified.

The NHS health technology assessment systematic review of endoscopic ultrasound in gastro-oesophageal cancer ${ }^{96}$ confirms the high accuracy of EUS for $\mathrm{T}$ and $\mathrm{N}$ staging of oesophageal and gastric cancer. Initial indications suggest that the performance for T staging at the cardia is less good. Radial probes performed better than linear probes in staging gastric cancer although in staging oesophageal cancer there was no 
significant difference between the two probes. Staging for metastases using EUS alone is not satisfactory.

\section{$M$ staging}

A review of 838 cases of newly diagnosed oesophageal cancers revealed that $18 \%$ have metastases at presentation ${ }^{97} ; 45 \%$ of metastases were in abdominal lymph nodes and $18 \%$ in cervical lymph nodes. In addition, $35 \%$ of metastases were hepatic, $20 \%$ pulmonary, $9 \%$ bone, $5 \%$ adrenal, $2 \%$ peritoneal, and $2 \%$ cerebral. In this series, all patients with bone and brain metastases were associated with metastatic disease in the abdomen and thorax. Hence, in the absence of clinical indications, evaluation of metastatic disease should be focused on examination of the thorax and abdomen.

The revised TNM classification ${ }^{73}$ includes some important changes relating to metastatic disease in gastro-oesophageal carcinomas. Tumours in the lower oesophagus with involved coeliac axis nodes or tumours in the upper oesophagus with involved cervical nodes are classified as Mla. Tumours of any region with other more distant metastases are classified as Mlb. There is therefore "overlap" in the process between $\mathrm{N}$ and $M$ staging.

Spiral CT has significantly improved the detection of hepatic metastases by the introduction of techniques using thinner collimation, overlapping slices, and dual phase imaging and will detect $75-80 \%$ of metastases. ${ }^{98}$ However, in patients with known malignancy, only $50 \%$ of lesions less than $1.5 \mathrm{~cm}^{99}$ and $12 \%$ of lesions less than $1 \mathrm{~cm}^{100}$ are metastatic deposits. Small volume ascites can also be readily demonstrated with EUS, alerting the surgeon to the possibility of diffuse peritoneal spread.

\section{Chest radiography}

A chest $x$ ray should only be requested in accordance with the Royal College of Radiologists guidelines ${ }^{101}$ and while the presence of a known malignancy suggests such a requirement, CT will be performed as part of the routine staging procedure and is far more sensitive for the detection of pulmonary metastases.

\section{Transabdominal ultrasound}

Liver ultrasound may be more appropriate than CT when there is good clinical evidence of liver metastases and treatment options are so limited that confirmation is all that is required prior to palliation. Ultrasound may also be used in conjunction with or as an alternative to MRI to help characterise indeterminate liver lesions identified using CT. Its routine use is not recommended.

\section{MRI}

To date there is no evidence that MR has advantages over spiral CT in T stage assessment of either oesophageal or gastric carcinoma. ${ }^{102} 103$ MR imaging of the liver may be used in specific cases such as in patients with documented allergy to intravascular contrast agents or to help characterise indeterminate liver lesions identified using $\mathrm{CT}^{104}$ Reports of the use of endoluminal MR are largely laboratory based and the few clinical studies have shown no advantage over EUS.

\section{Bronchoscopy}

CT and EUS combined are highly accurate in the assessment of tracheobronchial invasion from oesophageal tumours and bronchoscopy is not routinely required. It should however be available for use in patients where such imaging has raised suspicion but not certainty of such invasion.

\section{Laparoscopy}

Peritoneal disease can be difficult to detect with conventional imaging. Laparoscopy should be considered in those patients where there is suspicion of peritoneal spread on CT or EUS such as in the presence of small volume ascites. Its routine use following CT and EUS prior to consideration of radical resection is advocated in gastric cancer and in those gastrooesophageal junctional tumours where there appears to be a gastric component. ${ }^{105-107}$

\section{PATHOLOGY}

\section{Oesophageal cancer}

\section{Precursor lesions}

Oesophageal dysplasia

The presence of dysplasia in squamous epithelium suggests potential for malignant transformation. High grade dysplasia suggests malignant transformation has already occurred.

\section{Barrett's oesophagus}

Although Barrett's oesophagus is a well recognised entity, the pathological interpretation can be problematical. In essence Barrett's is characterised by three histological types: (i) gastric fundal type epithelium with mucous secreting cells; (ii) gastric junctional type epithelium with mucous secreting cells; and (iii) specialised columnar epithelium with mucous secreting goblet cells amounting to intestinal metaplasia. Macroscopically, most consider columnar epithelium over $3 \mathrm{~cm}$ or more above the gastro-oesophageal junction as Barrett's. However, Barrett's change can also affect segments less than $3 \mathrm{~cm}$ and may occur with or without intestinal metaplasia. The presence of intestinal metaplasia confers the risk of malignant transformation. Endoscopically, the changes appear as an irregular edge of pink mucosa with interspersed tongues of columnar epithelium in otherwise normal pale squamous epithelium.

The main significance of Barrett's oesophagus is the tendency to mucosal instability and the development of dysplasia which may progress to cancer. ${ }^{108}$ There is a tendency for longer segments to have a higher rate of dysplasia. Low grade dysplasia carries an increased risk of progressing to high grade dysplasia and malignant transformation. However, low grade dysplasia may undergo spontaneous regression. Indeed there can be regression associated with proton pump inhibitors with "healing" leaving a regenerative inflammatory atypia, which can be confused with high grade dysplasia. There are also problems with sampling error at biopsy and ensuring during endoscopic surveillance that the same area is biopsied. ${ }^{109}$ This is further complicated by an apparent inconsistent spatial relationship between the areas of dysplasia and areas of cancer in the same oesophagus. Such factors have led to a lack of agreement between pathologists as to the definition of dysplasia. More accurate markers are required for the loss of growth regulation in the specialised columnar epithelium of Barrett's and developments in molecular and chromosomal techniques may aid a more uniform approach.

\section{Biopsy reporting}

Biopsy specimens should be examined by an experienced histopathologist. Any unusual findings such as high grade dysplasia in Barrett's should be corroborated by a separate pathologist-a "lead pathologist" in gastrointestinal pathology. Cytological examination should be performed by an experienced cytopathologist. Unusual tumour types, although rare, may require further investigation. If possible, the presence of submucosal invasion should be identified in a biopsy specimen as this increases the likelihood of lymph node metastases. ${ }^{110}$

\section{Surgical specimen reporting}

Reporting surgically resected specimens for oesophageal cancer should include the principal prognostic factors. These are detailed in the Royal College of Pathologists minimum dataset for the reporting of oesophageal tumours. ${ }^{111}$ Briefly, a report should include comments on the type of tumour, depth of invasion (using the TNM staging system ${ }^{73}$ ), involvement of the 
resection margins, vascular invasion, ${ }^{109}$ and lymph node involvement. There is currently limited evidence that involvement of the circumferential resection margin indicates a worse prognosis. ${ }^{112}$ Where possible, involvement of this margin should be specified ( separate dissection of the lymph nodes by the surgeon before sending the specimen to the pathology department may make examination of this margin impossible). There is a widespread network of lymphatic vessels in the oesophagus allowing intramural spread of tumour which may not be macroscopically evident. Satellite nodules of tumour may be very close to the proximal resection margin in spite of good macroscopic clearance. ${ }^{113}$

\section{Gastric cancer \\ Precursor lesions}

\section{Gastritis and intestinal metaplasia}

There is now a large body of evidence to support the Correa hypothesi ${ }^{27}$ of a progression from chronic gastritis to gastric atrophy with intestinal metaplasia to dysplasia prior to malignant transformation. Some of the early relationships between these changes are reversible. Gastric mucosa shows atrophy with age.

The relationship between the three types of intestinal metaplasia and the intestinal type of gastric cancer is at present unclear. Types 1 and 2 or complete intestinal metaplasia tend to be associated with ageing gastric atrophy and have a minimal chance of malignant transformation. Type 3 or incomplete intestinal metaplasia has a greater chance of progression to dysplasia. ${ }^{114}$

\section{Dysplasia}

The grading of gastric dysplasia is subjective and open to significant interobserver variation. To simplify (from the previous mild moderate and severe dysplasia) and to overcome this problem, low and high grade groupings are used. ${ }^{115}$ Patients with high grade dysplasia on more than one examination are very likely to have an ACA. ${ }^{116}$ However, the diagnosis of dysplasia is difficult and can be confused with regenerative changes. Consideration of referral of biopsies with severe dysplasia to a reference pathologist or pathologists should be encouraged. Reference pathologists are linked to the British Society of Gastroenterology, the Medical Research Council Gastric Planning Group, and the UK National Barrett's Oesophagus Registry.

\section{Biopsy reporting}

The majority of diagnoses are obtained from standard $\mathrm{H}$ and $\mathrm{E}$ preparations. Endoscopic biopsy can be supplemented by brush cytology. In patients with anaplastic tumours, immunocytochemical staining should be available to differentiate from lymphoma.

Peritoneal washings taken at laparoscopy need to be examined cytologically and can provide valuable information about free peritoneal cells. This is significant as patients with free intraperitoneal cells have a poor prognosis with disseminated intraperitoneal recurrence and should be considered incurable by surgery alone. ${ }^{117}$

\section{Surgical specimen reporting}

The principal prognostic factors for gastric ACA are the depth of penetration of the tumour and lymph node involvement. ${ }^{117}$ In addition, the macroscopic appearance (Borrman type), tumour location, and histological differentiation are important prognostic variables. The resection margins of the specimen need to be examined and reported.

The assessment of lymph nodes should include a full dissection of the specimen to define the total lymph node number removed and the total involved by tumour. The TNM staging system ${ }^{73}$ allocates nodal stage according to the number of lymph nodes involved. Most specimens will contain a minimum of 12 nodes for examination.
Malignant tumours of the stomach are usually ACA although $10 \%$ comprise lymphoma, leiomyosarcoma, and carcinoid. A range of classifications have been suggested for gastric ACA-Ming (which classifies the tumour border as being infiltrative or expansile), WHO (with a range of histopathology descriptions), Goseki (dividing tumours according to whether they have good tubal formation and intracellular mucin), and Lauren (diffuse, intestinal, and mixed types). The Lauren classification is the most widely used but only identifies a relatively small subgroup of poor prognosis gastric ACA (the diffuse carcinomas). Other factors, which have been assessed, include vascular invasion and perineural invasion. Vascular invasion is an independent prognostic variable in cardial $^{118}$ and distal tumours. ${ }^{119}$ Perineural invasion is of questionable value and requires more specific definition. ${ }^{120}$

\section{Oesophagogastric junction cancers}

ACA arising at the oesophagogastric junction pose many problems. They are difficult to classify as they can arise from the columnar lined lower oesophagus, from the cardia itself, or from the gastric body/fundus, with upward spread to involve the oesophagus. The surgical procedures advocated to treat these tumours remain varied and controversial. True cardia tumours behave in a more aggressive fashion than oesophageal tumours. ${ }^{118} 121$

The Japanese Society for Esophageal Disease ${ }^{122}$ originally classified carcinomas of the gastro-oesophageal junction as $\mathrm{E}=\mathrm{C}$, where equal parts of the tumour lie within the oesophagus and stomach, and is either EC or CE where the bulk of the tumour lies in the oesophagus and stomach, respectively. Compton and Sobin ${ }^{123}$ have proposed that if more than $50 \%$ of the tumour involves the stomach then it should be regarded as gastric while if more than $50 \%$ is within the oesophagus then it should be reported as an oesophageal tumour. Those tumours of equal proportions above and below the junction are classified according to their histology and then subdivided into either oesophageal or gastric. Squamous, small cell, and undifferentiated tumour types are regarded as oesophageal while ACA (including Signet ring type) are classified as gastric. This classification is an oversimplification as it does not identify true tumours of the cardia itself.

Siewert and Stein ${ }^{124}$ have proposed a classification based on the three origins of oesophagogastric tumours mentioned above. Their type I tumour is an ACA of the distal oesophagus, the centre of the tumour lying $1-5 \mathrm{~cm}$ above the anatomical cardia. A type II tumour is a true carcinoma of the cardia with its centre situated between $1 \mathrm{~cm}$ above and $2 \mathrm{~cm}$ below the anatomical cardia; the type III tumour is a gastric carcinoma with its centre between 2 and $5 \mathrm{~cm}$ below the anatomical cardia. It is argued that these three types of tumours require different surgical approaches to ensure clear surgical margins and also because of differing patterns of lymph node metastases making the extent of lymphadenectomy different for each type of tumour. Lymphatic spread from type I lesions occurs in a cephalad direction to mediastinal nodes as well as caudally to the coeliac axis, whereas type II and III lesions metastasise almost exclusively caudally to the coeliac axis, splenic hilum, and para-aortic nodes. ${ }^{125}$ This classification is recommended as it is uniform, allows data comparison from different centres, and is important for the stratification of patients in prospective studies.

\section{PRETREATMENT ASSESSMENT}

Careful selection of the varying therapeutic modalities is essential. Such selection should consider not only the nature of the symptoms to be relieved but also the general medical and psychological status of the patient. Decisions should be taken in the context of the predicted prognosis and the effect of any treatment intervention on quality of life. A close multidisciplinary team working with integrated liaison between 
primary and secondary care is therefore required to facilitate a holistic approach to patient care. This approach must ensure that patients are provided with the information they wish to have, in terms that they are able to understand, and in an efficient and timely manner. It is recommended that a fully constituted specialist multidisciplinary team with careful documentation of the proposed treatment plan assess all patients.

\section{PREOPERATIVE ASSESSMENT}

The likely benefit derived from a particular therapy depends not only on the stage of the oesophageal or gastric disease but also on the fitness of the patient. The patient's preoperative physiological status is a major factor in determining outcome after major surgery. ${ }^{126-129}$ Although scoring systems including a variety of parameters have been evaluated, the previous medical history and concurrent morbidity remain the strongest predictors. ${ }^{126}$

Comprehensive preoperative evaluation and assessment of the patient is mandatory before assigning the patient to a particular therapeutic option. Where potential problems have been identified, early communication with the anaesthetic team is essential. Preoperative assessment and optimisation may necessitate a multidisciplinary approach.

Anaesthetists familiar with the complexities of one lung ventilation and epidural anaesthesia should only undertake anaesthesia for oesophageal surgery. In such patients perioperative invasive monitoring should be routine. ${ }^{130}$

Appropriate postoperative facilities for aftercare must be available prior to undertaking surgery. ${ }^{131}{ }^{132}$

\section{Past medical history}

A detailed medical history and physical examination is a prerequisite to the assessment of any anaesthetic and operative risk. Cardiorespiratory disease has been identified as the commonest coexisting disease in patients presenting for oesophagectomy. ${ }^{132}$ Pre-existing ischaemic heart disease, poorly controlled hypertension, and pulmonary dysfunction are all associated with increased operative morbidity, ${ }^{127-129}$ 133-135 particularly in the elderly and following upper abdominal and thoracic surgery. The efficacy of any medication prescribed for cardiorespiratory conditions should be evaluated at an early stage.

The American Society of Anesthesiologists (ASA) classification of physical status is well recognised. Perioperative risk increases with increasing ASA score. Only those patients with an ASA score of 3 or less should be considered for surgery. ${ }^{134} 136$

\section{Social habits}

Smoking is a significant aetiological factor in perioperative morbidity. All patients must be encouraged to stop smoking preoperatively. ${ }^{137}$

\section{Preoperative investigations}

The minimum preoperative investigations for all patients undergoing gastric or oesophageal surgery should include baseline haematological and biochemical profiles, arterial blood gases on air, pulmonary functions tests, a resting electrocardiogram, and a chest $x$ ray.

Exercise capacity and testing can be informative as regards a patient's cardiorespiratory reserve. ${ }^{138-140}$

Patients with known or symptomatic ischaemic heart disease need careful evaluation, ${ }^{141}{ }^{142}$ often in collaboration with specialist colleagues. More detailed investigations such as exercise electrocardiography, echocardiography, thallium imaging, and V/Q scanning may be considered appropriate in some of these patients. ${ }^{143}$

Pulmonary complications are increased when $\mathrm{FEV}_{1}$ is reduced by $20 \%$ or more. ${ }^{144-146}$ However, in evaluating pulmonary function tests consideration must be given to the fact that setting strict exclusion criteria as regards acceptable values may deny patients their only chance of curative surgery. Pulmonary function tests must be considered in relation to those appropriate for individual height and weight, the clinical findings and arterial blood gas analysis, particularly $\mathrm{PaO}_{2}$.

\section{Preoperative preparation}

Coexisting disease

All patients should be rendered optimally fit in the preoperative period before undertaking anaesthesia for gastric or oesophageal surgery.

Pharmacological treatment of angina, hypertension, asthma, and COPD should be optimised. Preoperative chest physiotherapy may be beneficial. Where appropriate, haematological and biochemical abnormalities should be corrected.

\section{Nutritional status}

Patients at their ideal body weight may do better after surgery. A body mass index of less than 18.5, body weight less than $90 \%$ predicted, over $20 \%$ weight loss, and a low serum albumin are associated with an increased risk of perioperative complications. ${ }^{136}{ }^{146}$ Obesity is associated with increased operative risk. ${ }^{147}$

\section{Psychological preparation}

All patients should be counselled about treatment options, paying particular attention to the results and limitations of surgery. A clear description of the perioperative period should be given. An assessment of pretreatment symptoms on quality of life of the patient should be carefully undertaken as there is accumulating evidence of quality of life scores having an independent effect on outcome. ${ }^{148}$

\section{Thromboembolic prophylaxis}

Appropriate measures should be taken against the risk of thromboembolic complications. Antithromboembolic stockings, low molecular weight heparin, and peroperative calf compression should be employed. ${ }^{149}$

\section{Antibiotic prophylaxis}

Broad spectrum antibiotic prophylaxis should be administered preoperatively, or on induction of anaesthesia, in accordance with locally agreed policies.

\section{Blood cross match}

Four units of blood should be cross matched prior to surgery. Transfusion however should be avoided if at all possible as the immunological suppressive effect can adversely affect survival. ${ }^{150}$

\section{SURGICAL RESECTION FOR OESOPHAGEAL CANCER General rationale}

Resection of oesophageal malignancy with intent to cure is based on the concept that if all neoplastic tissue can be removed a worthwhile period of survival and possible cure might be achieved. Surgical therapy is the only treatment that has repeatedly been shown to provide prolonged survival, albeit in only approximately $20 \%$ of cases. ${ }^{151}$ The results of surgical resection for both early stage squamous cell and ACA can be excellent. Five year survival rate is over $80 \%$ when tumours are confined to the mucosa and between $50 \%$ and $80 \%$ when the submucosa is involved. ${ }^{152}{ }^{153}$ Conversely, resection has no place in patients with haematogenous metastases. ${ }^{154}$

It is essential that oesophagectomy should be undertaken with a low hospital mortality and complication rate. Case selection, case volume, and surgical experience all play an important part. Preoperative risk analysis has been shown to cause a reduction in postoperative mortality from $9.4 \%$ to 
$1.6 \% .{ }^{155}$ In 1986, Matthews et al demonstrated a negative correlation between the number of carcinomas resected and hospital mortality among surgeons in the West Midlands. ${ }^{156} \mathrm{~A}$ team based approach and increasing expertise within that team has also demonstrated a significant decrease in the mortality of oesophagectomy over time. . $^{157-161}$

In an extensive literature review of studies reported between 1980 and 1988 it was confirmed that the average hospital mortality following resection was 13\%. ${ }^{151}$ Many European centres have reported hospital mortalities well below this figure throughout the 1990s and it must be accepted that a hospital mortality of less than $10 \%$ should now be achievable.

\section{Selection of patients for surgery}

Patient selection for radical intervention is based on the stage and spread of the tumour and the general and specific medical fitness of the patient. A specialist oesophagogastric cancer team in discussion with the patient and his/her family should make treatment decisions. Patients for whom radical intervention is inappropriate (T4 tumours) may be best treated in local cancer units. However, the specialist oesophagogastric cancer team should be involved in developing an appropriate care plan for these patients.

Radical surgery should be recommended for patients with localised $(\mathrm{T} 1, \mathrm{~T} 2)$ tumours who are sufficiently fit to tolerate the procedure. Combination therapy should be considered for T2 tumours (see below). Patients with advanced oesophageal cancer (T3N1) should be considered for randomised controlled studies to assess the role of novel multimodality therapies in combination with surgery.

\section{Choice of operative approach}

The histological tumour type, its location, and extent of the proposed lymphadenectomy should determine the operative approach. Adequate mediastinal lymphadenectomy is essential in SCC but needs to be extended to the abdomen in junctional ACA. This makes transhiatal oesophagectomy unsuitable for SCC. A left thoracoabdominal approach is limited proximally by the aortic arch which may compromise the proximal limit of resection. Tumours which lie at the level of the arch are difficult to deal with from the left side and this approach should be avoided when the tumour lies at this level or higher. The most widely practised approach is the two phase Lewis-Tanner, with a preliminary laparotomy and construction of a gastric tube and a right thoracotomy to excise the tumour and perform an oesophagogastric anastomosis at the apex of the mediastinum. A third cervical phase may be added in the case of proximally situated tumours in order to achieve the requisite degree of longitudinal clearance.

\section{Standards of tumour resection}

All operations should deal adequately with the local tumour to minimise the risk of local recurrence and permit an adequate lymphadenectomy, which will reduce the risk of staging error. The extent to which lymphadenectomy per se minimises the risk of symptomatic local recurrence is not known. The evidence that more thorough lymphadenectomy is associated with better survival may simply reflect more accurate staging.

Longitudinal submucosal spread is characteristic of all types of oesophageal carcinoma. This accounts for a high rate of resection margin positivity, when limited longitudinal resections are employed, even with negative frozen section biopsy margins. ${ }^{162}$ Extensive studies ${ }^{163-165}$ support the view that the proximal extent of resection should ideally be $10 \mathrm{~cm}$ above the macroscopic tumour and $5 \mathrm{~cm}$ distal to it, when the oesophagus is in its natural state. Local recurrence can be minimised in this situation by the use of postoperative radiotherapy ${ }^{166}$ and this should be considered in SCC, particularly when the proximal level of the tumour is high.

ACA of the lower oesophagus commonly infiltrates the gastric cardia, fundus, and lesser curve. Some degree of gastric excision is essential to accomplish an adequate lymphadenectomy in the abdomen and this should be created in such a way as to obtain a minimum distance of $5 \mathrm{~cm}$ beyond the distal extent of the macroscopic tumour. It is interesting to note however that positive distal resection margins in ACA are often found in patients with locally advanced disease where the resection in retrospect was unlikely to be curative. Most of these patients do not die from symptomatic locoregional recurrence. ${ }^{167}$

Adequate radial margins should also be considered and contiguous excision of the crura and diaphragm need to be considered, particularly for junctional tumours. ${ }^{168}$

\section{Standards of lymphadenectomy}

The majority of patients who undergo surgery for either ACA or SCC of the oesophagus will have lymph node metastases. ${ }^{151}$ The principal aims of lymphadenectomy should be to minimise staging error, reduce locoregional risks of recurrence and, by increasing the number of patients undergoing an R0 resection, increase five year survival (R0 resection: complete macroscopic and microscopic clearance). ${ }^{154}{ }^{169}$ In SCC, when a methodical approach to lymphadenectomy is applied, the numbers of lymph nodes involved are of prognostic significance ${ }^{170}$ as is the ratio of invaded to removed nodes. ${ }^{169}$ Although there is considerable enthusiasm for the performance of lymphadenectomy in three fields (abdomen, thorax, and neck) in Japan, ${ }^{170}$ this approach has not been adopted widely by Western surgeons.

Abdominal single field node dissection involves dissection of the right and left cardiac node, the nodes along the lesser curvature, left gastric, hepatic, and splenic artery territories.

Two field dissection additionally embraces thoracic lymphadenectomy and includes the para-aortic nodes along with the thoracic duct, para-oesophageal nodes, right and left pulmonary hilar nodes, those at the tracheal bifurcation and, in Japan, para-tracheal nodes including those along the left recurrent laryngeal nerve.

Three field dissection extends the lymphadenectomy to the neck to clear the brachiocephalic, deep lateral, and external cervical nodes, and the deep anterior cervical nodes adjacent to the recurrent laryngeal nerve chains in the neck.

A number of studies have shown that two field lymphadenectomy can be carried out without any significant increase in operative morbidity or mortality. ${ }^{154} 170$

Conversely, although the three field operation is advocated in Japan for SCC, its benefits may simply reflect the reduction in staging error, as nearly a quarter of all Japanese patients will have cervical lymph node metastases. ${ }^{170}$ There is no evidence that three field lymphadenectomy improves survival in patients with ACA and it must be accepted that the operation is associated with a higher risk of postoperative morbidity (see below).

\section{Choice of conduit, route, and anastomosis}

The commonest conduit is the stomach. The function of the intrathoracic stomach as an oesophageal replacement has been extensively studied. ${ }^{172}$ The necessary vagotomy can produce troublesome gastric paresis. A prospective randomised trial suggested that the addition of a drainage procedure did not affect gastric emptying or clinical outcome although it was too small to reach statistical significance. ${ }^{173}$ Thus since the morbidity of pyloroplasty is small, its addition should be considered. Colon interposition is the next most suitable conduit when the stomach is not available. Again, functional performance has been studied in detail. ${ }^{174}$

Most surgeons favour a prevertebral route for reconstruction and this was shown to be superior to an anterior reconstruction in one randomised study ${ }^{175}$ although another small prospective randomised comparison with a retrosternal gastric tube showed no differences in technical complications or functional outcome. ${ }^{176}$ 
The level at which the anastomosis is performed is the subject of continued debate. There are no randomised trials to compare subtotal oesophagectomy with anastomosis in the neck or oesophagogastrectomy with anastomosis in the superior mediastinum. Each has its proponents. Until and if such a trial is undertaken, the fundamental premise must be the presence of clear longitudinal resection margins and an acceptable morbidity and mortality.

Both retrospective and prospective studies comparing manual versus mechanical oesophagogastric anastomosis have shown no difference in leak rates or other complications. ${ }^{177} 178$ Fewer strictures occur with handsewn anastomoses particularly single layer anastomoses. ${ }^{179}$

\section{Postoperative management}

Meticulous attention to the maintenance of fluid balance and respiratory care are essential in the immediate postoperative period. Pain control and pulmonary physiotherapy are crucial. Although some authors advocate the routine use of a feeding jejunostomy, there have been no prospective trials to examine its value. ${ }^{180}$ Early mobilisation is important in the prevention of venous thrombosis and pulmonary embolism.

\section{Postoperative complications}

\section{Pulmonary}

Respiratory complications are common following oesophagectomy. Pain from extensive incisions can be a major contributor to decreased ventilation and atelectasis, leading to pneumonia and respiratory failure. Incisions of the diaphragm may impair its movement and extensive lymphadenectomy can cause poor lymphatic drainage of the pulmonary alveoli, resulting in a form of acute pulmonary oedema. ${ }^{181-183}$ The use of thoracic epidural anaesthesia has been shown to significantly decrease the incidence of respiratory complications. ${ }^{184}$

\section{Anastomotic leakage}

Early disruption (within the first 72 hours) usually reflects technical error. Once confirmed, if the general condition of the patient is good, then re-exploration and repair is appropriate. The majority of disruptions occur later (up to two weeks) and probably reflect local ischaemia and/or tension in the anastomotic site. A high index of clinical suspicion is important. Although water soluble contrast radiology should be used to establish that leakage has occurred, the technique is not completely accurate and may miss clinically significant leaks as well as demonstrate radiological leakages of no clinical significance. ${ }^{185} 186$ The majority of anastomotic leakages, whether in the neck or the chest, can be managed conservatively with nasogastric suction, appropriate local drainage, antibiotics, and jejunal feeding. Dehiscence of the gastric resection line is usually due to ischaemia and is dramatic in its presentation. Early endoscopy may be considered if radiology is inconclusive. Re-exploration is essential. ${ }^{187}$

There seems to be no real difference in clinically significant leak rates and subsequent effects comparing neck and chest anastomoses. Placement of an anastomosis in the neck does not guarantee that leakage will not be into the thoracic cavity ${ }^{188}$ The overall anastomotic leak rate should not exceed $5 \% .{ }^{151}$

\section{Chylothorax}

Chylothorax occurs in about 2-3\% of transthoracic oesophagectomies. It is easily recognised as turbid creamy fluid in the chest drain. The rate may be higher with transhiatal oesophagectomy although this is not always the case. ${ }^{189-192}$ The condition has a high mortality if conservative treatment becomes prolonged due to hypoalbuminaemia and leucocyte depletion. ${ }^{189}$ The rate of chyle output on about the fifth postoperative day may predict the likelihood of spontaneous closure. Chyle production of greater than $10 \mathrm{ml} / \mathrm{kg} /$ day at that time is an indication for early reoperation and ligation of the thoracic duct. ${ }^{192}$

\section{Recurrent laryngeal nerve injury}

Recurrent laryngeal nerve injuries are more common during dissection of the upper third of the oesophagus. The majority of injuries are unilateral and transient. The left recurrent laryngeal nerve is at risk during mediastinal lymphadenectomy and if cervical anastomosis is used in association with such a dissection, it is wiser to place this on the left side in order to minimise the risk of damage to both recurrent laryngeal nerves. Recurrent laryngeal nerve injury impairs the patient's ability to cough in the early postoperative period and adequately protect the airway during swallowing. It can therefore be a potent contributor to pulmonary morbidity. In most patients there is adequate compensation from the opposite cord. Tracheostomy should be considered to protect the airway and improve pulmonary toilet. Thyroplasty or vocal cord injections are rarely required. ${ }^{193}$

\section{Benign anastomotic stricture}

These can occur within the first few months after surgery, where they relate to postoperative fibrosis, or late (that is, years), when they are due to reflux. Differentiation from suture line recurrence can be difficult at early stages and biopsy is essential. The incidence of early anastomotic stricture formation seems to be higher with cervical rather than intrathoracic anastomoses and in stapled procedures, particularly if a small circular stapler is used. ${ }^{194-196}$ These early postoperative anastomotic strictures are easily dealt with by endoscopic dilatation although multiple sessions may be necessary. ${ }^{197}$

\section{SURGICAL RESECTION FOR GASTRIC CANCER Curative surgery}

Surgery is the treatment of choice for gastric cancer. The most important variable for resectability and survival after surgery is the stage of disease at presentation. In the West Midlands survey, $80 \%$ of patients presented with stage IV disease and only $20 \%$ underwent curative resection. ${ }^{24}$ In a review of English language publications in the decade to 1990, Akoh and Macintyre ${ }^{198}$ reported a mean resection rate of $48 \%$ with only $31 \%$ having "curative" or R0 resection. In the UK Medical Research Council multicentre D1 lymphadenectomy versus D2 extended lymphadenectomy trial, only 54\% of patients deemed suitable for inclusion within the trial protocol actually underwent a potentially curative resection. ${ }^{199}$ The increasing availability of endoscopy and the recommendation to investigate patients with new onset dyspepsia promptly has led to improved resectability rates. ${ }^{537}$

\section{Extent of gastric resection}

Gastric cancer behaves as a locoregional disease with late distant metastasis in a significant proportion of cases. The Japanese Rules for Gastric Cancer ${ }^{17}$ have described the criteria for margins of macroscopic clearance according to the site of the lesion and macroscopic size. A subtotal gastrectomy is appropriate for an early or well circumscribed T2 cancer if the proximal edge is more than $2 \mathrm{~cm}$ from the cardia. There needs to be a $5 \mathrm{~cm}$ clearance for a more infiltrative lesion. When the proximal distance is less than $5 \mathrm{~cm}$ or the tumour is diffuse with submucosal infiltration, a total gastrectomy is indicated. A proximal oesophageal margin of $5 \mathrm{~cm}$ in the natural state is necessary for type III junctional tumours. Total gastrectomy with abdominal lymphadenectomy should also be considered for type II tumours. Resection of adjacent organs when there is definite or suspected transmural invasion (T4 cancers) may be worthwhile provided no macroscopic residual disease will remain and the patient is fit enough to undergo radical surgery. ${ }^{200}$ 
Less extensive resections are now commonly performed in Japan in selected patients with early gastric cancer. These resections may be open, laparoscopic, or using an operative gastroscope. The high incidence of node positive early gastric cancer in the West means that limited resections may not be curative. ${ }^{201}$

\section{Lymphadenectomy}

Japanese experience has shown that excision of the primary lesion together with the omenta and first two tiers of lymph nodes ( $\mathrm{N} 1$ and $\mathrm{N} 2$ ) that drain the affected area of the stomach can cure patients even in the presence of lymph node metastases-D2 or systematic lymphadenectomy. If other nodes beyond the second tier are resected (for example, nodes in the hepatoduodenal ligament) then this is an extended lymphadenectomy. In the Japanese rules for surgery, ${ }^{142}$ a resection is regarded as curative if all evidence of cancer is removed (R0). A resection is "absolute curative" if at least one tier of nodes beyond those affected is removed (for example, $\mathrm{D} 2$ lymphadenectomy for $\mathrm{N} 0$ or $\mathrm{Nl}$ cancer). A resection of only the first tier of nodes is a Dl or limited lymphadenectomy and this has historically been the level of resection achieved by the majority of surgeons in the West. Overall five year survival rates are not helpful for comparing surgical results. Comparison of stage dependant survival rates for Japanese and Western series show significantly poorer results in the West. ${ }^{198}$ However, better results with more extensive lymph node resection are partly due to more accurate pathological staging of cancers (stage migration factor) and cannot be attributed to the effects of surgery alone. In an attempt to emulate the Japanese experience, some specialised Western surgeons have achieved similar survival rates with D2 lymphadenectomy at least in the earlier stages of the disease..$^{5322}$ The advantage of D2 resection appears mainly confined to stages II and IIIa. ${ }^{203} \mathrm{~A}$ proportion of patients with N2 disease are cured by D2 lymphadenectomy. This of course makes the assumption that they would not have stood a chance of cure with a lesser procedure. $^{204205}$

There are no Japanese randomised studies comparing Dl and $\mathrm{D} 2$ resections. There are now two completed multicentre trials in the West. Neither the MRC trial nor the Dutch trial have demonstrated a survival benefit for $\mathrm{D} 2$ over $\mathrm{D} 1$ resection for resectable gastric cancer. ${ }^{206} 207$ Mortality was significantly higher for D2 resection in both trials, particularly when the distal pancreas and spleen were excised as part of the lymph node clearance. While there has been criticism of these trials, they are likely to be representative of the limitations of current gastric cancer surgery in the West. However, the International Gastric Cancer Association consensus view in 1997 was that patients with curable gastric cancer should undergo a D2 resection

\section{Resection of the spleen and distal pancreas}

There is increasing evidence that removal of the spleen has an adverse effect on prognosis. ${ }^{208} 209$ The likelihood of positive splenic hilar nodes has to be considered carefully. They are rare in curable cancers of the distal two thirds of the stomachantrum $<1 \%$, middle third $<10 \%{ }^{210}$ The incidence is higher in more advanced but surgically incurable cancers. Resection of the hilar nodes without splenectomy is technically feasible but is still under investigation in specialised centres in the West.

Resection of the distal half of the pancreas to allow removal of the nodes along the splenic artery is associated with significant morbidity in both Japanese and Western patients. Complications related to distal pancreatectomy have been the major cause of death in Western studies. The MRC trial showed that patients who underwent a pancreaticosplenectomy had a worse prognosis than those who did not, although other factors may have contributed. ${ }^{206}$ Excision of the splenic artery nodes without pancreatectomy is feasible. ${ }^{211}$ Applica- tion of such techniques in Western patients is currently being explored.

\section{Morbidity and mortality}

Multiple factors affect the mortality of curative gastric cancer surgery, including age and fitness of the patients, and the stage and position of the cancer. Palliative operations are associated with a higher mortality. The mortality of total gastrectomy is approximately twice that of a subtotal gastrectomy. At present the mortality of D2 resection is higher than that of a more limited lymph node resection (D1) although much of the excess risk has been related to the high complication rate of distal pancreatectomy and splenectomy. In the West there is evidence of a learning curve for D2 resections. ${ }^{212}$ Results from specialised units have reported operative mortality of $5 \%$ or less. ${ }^{53}{ }^{202}$ Registry data have shown a lower operative mortality for those surgeons performing nine or more resections per year. ${ }^{24}$ In a review of non-specialised surgeons there was considerable variation in operative mortality but in fact the surgeon performing most resections did not have the lowest morbidity and mortality. ${ }^{213}$ Although there is no evidence to support a specific critical mass for the number of radical gastric resections a surgeon should perform, results from specialised units with appropriate multidisciplinary teams suggest an advantage in concentrating expertise and experience in treating patients with all stages of the disease.

\section{ADJUVANT TREATMENT \\ Oesophageal cancer}

\section{Adjuvant chemotherapy}

The use of postoperative chemotherapy in oesophageal disease is problematical given the recovery period that commonly follows oesophagectomy. This delay conflicts with the aims of adjuvant therapy. Evidence regarding postoperative therapy is limited. A randomised trial of two cycles of postoperative cisplatin and vindesine versus surgery alone in 205 patients showed no significant difference in survival. ${ }^{214}$ In a subsequent study using cisplatin and 5-FU in 242 patients, there was an effect on disease free five year survival but there was no overall five year survival benefit (surgery $51 \% \quad v$ surgery/ chemotherapy $61 \%$; $p=0.3) .{ }^{215}$ There is therefore no evidence to use adjuvant chemotherapy outside the setting of a clinical trial.

\section{Neoadjuvant chemotherapy}

An initial randomised trial of pre and postoperative cisplatin and 5-FU versus surgery alone demonstrated no benefit from the addition of chemotherapy. However, very few patients actually received the full course of chemotherapy allocated in this study. ${ }^{216} \mathrm{~A}$ second multicentre randomised trial including 802 patients compared two cycles of preoperative cisplatin and 5-FU with surgery alone. This demonstrated a statistically significant survival benefit for the chemotherapy treated group (median survival 530 days $v 408$ days; $\mathrm{p}=0.002$ ). Furthermore, there was no difference between the two arms in the number of perioperative deaths or the rate of postoperative complications (unpublished data from the UK Medical Research Council OEO2 Trial). These results argue in favour of preoperative chemotherapy for all patients with operable oesophageal cancer other than those with unequivocally $\mathrm{Tl}$ tumours.

\section{Preoperative radiotherapy}

A meta-analysis of five randomised trials comparing preoperative radiotherapy with surgery alone failed to detect a significant benefit of radiotherapy (hazard ratio 0.89 ; 95\% confidence interval (CI) $0.78-1.01 ; \mathrm{p}=0.062) .{ }^{217}$

\section{Neoadjuvant chemoradiation}

Five randomised trials have compared chemoradiation and surgery with surgery alone in operable carcinoma of the 
Table 3 Trials of neoadjuvant chemoradiation followed by surgery in oesophageal cancer

\begin{tabular}{|c|c|c|c|c|c|c|}
\hline Trial & Treatment $\operatorname{arm}(\mathrm{s})$ & $\begin{array}{l}\text { No of } \\
\text { patients }\end{array}$ & Histology and stage & $\begin{array}{l}\text { No complete } \\
\text { resections/No } \\
\text { operations }\end{array}$ & $\begin{array}{l}\text { Path CR } \\
\text { rate }\end{array}$ & $\begin{array}{l}\text { Survival (median unless } \\
\text { otherwise stated) }\end{array}$ \\
\hline Poplin ${ }^{223}$ & Cisplatin/5-FU/RT & 113 & Squamous stage I-III & $32 / 71$ & $16 \%$ & 12 months \\
\hline Forastiere $^{224}$ & Cisplatin/vinblastine/5-FU/RT & 43 & Squamous and adeno stage $|-| I \mid$ & $36 / 41$ & $23 \%$ & $>26$ months \\
\hline Gray $^{225}$ & Paclitaxel/ Carboplatin/5-FU/RT & 73 & Squamous and adeno stage I-III & $56 / 59$ & $54 \%$ & 24 months \\
\hline $\operatorname{Stahl}^{226}$ & Cisplatin/5-FU/leucovorin/RT & 25 & Squamous and adeno stage II-III & $16 / 19$ & $40 \%$ & $>16$ months \\
\hline \multirow[t]{4}{*}{ Nygaard $^{218}$} & Cisplatin/ bleomycin & 50 & Squamous stage I-II & NR & NR & 8 months \\
\hline & RT & 48 & & & & 11 months \\
\hline & Cisplatin/bleomycin/RT & 47 & & & & 9 months \\
\hline & Surgery alone & 41 & & & & 8 months \\
\hline \multirow{2}{*}{ Le Prise ${ }^{219}$} & Cisplatin/5-FU/RT & 41 & Squamous stage I-II & $35 / 35$ & $10 \%$ & 10 months \\
\hline & Surgery alone & 45 & & $38 / 42$ & - & 10.5 months \\
\hline \multirow[t]{2}{*}{ Bosset $^{221}$} & Cisplatin/RT & 143 & Squamous stage I-II & $112 / 138$ & $21 \%$ & 18.6 months \\
\hline & Surgery alone & 139 & & $94 / 137 *$ & - & 18.6 months \\
\hline \multirow[t]{2}{*}{ Walsh $^{220}$} & Cisplatin/5-FU/RT & 58 & Adeno stage I-III & NR & $25 \%$ & 16 months \\
\hline & Surgery alone & 55 & & & - & 11 months* \\
\hline \multirow[t]{2}{*}{$U_{r b a}^{222}$} & Cisplatin/vinblatine/5-FU/RT & 50 & Squamous and adeno stage I-II & NR & $28 \%$ & $32 \% 3$ year \\
\hline & Surgery alone & 50 & & NR & - & $15 \% 3$ year* \\
\hline
\end{tabular}

* Statistically significant difference.

NR, not reported; RT, radiotherapy; 5-FU, 5-fluorouracil; CR, complete response.

oesophagus (irrespective of histology) (table 3). ${ }^{218-222}$ Three of these trials have not shown a survival advantage for preoperative chemoradiation but may be criticised on the basis of inadequate chemotherapy ${ }^{218} 221$ or radiotherapy ${ }^{219} 221$ doses. Chemotherapy and radiotherapy were also administered sequentially rather than concurrently in one trial. ${ }^{219}$ The two positive studies used chemoradiation protocols incorporating cisplatin and 5-FU, with concurrent 40 or 45 Gy radiotherapy. A metaanalysis of the five trials showed an overall improvement in three year survival from $22 \%$ with surgery alone to $31 \%$ with preoperative chemoradiation. The odds ratio for survival in favour of chemoradiation was 1.62 (95\% CI $1.17-2.26)$. Current interest is focusing on the development of more effective combination regimens using newer chemotherapeutic agents such as the taxanes together with cisplatin and 5-FU, administering continuous low doses of cytotoxic agents throughout radiotherapy, and delivering radiotherapy in hyperfractionated twice daily schedules.

\section{Definitive chemoradiation for localised SCC}

SCC typically presents in the proximal oesophagus and therefore represents a greater surgical challenge than the typical ACA of the lower third. Furthermore, patients often present at an advanced age, and may be poor surgical candidates. In non-randomised comparisons concurrent chemoradiation has produced pathological complete response rates consistently above $20 \%$ in those who went on to have subsequent surgery (table 3). The median survival for patients treated with chemoradiation is similar to those treated with surgery alone. Chemoradiation and surgery thus appear equivalent modalities in SCC of the proximal oesophagus.

\section{Gastric and oesophagogastric junction cancer \\ Adjuvant chemotherapy}

The rationale that postoperative chemotherapy may improve local and systemic control and ultimately survival has been under investigation for 25 years. A meta analysis of randomised trials has failed to show a benefit for chemotherapy over surgery alone (odds ratio 0.88 (95\% CI $0.78-$ 1.08)).227 However, subsequent inclusion of a further two studies did suggest advantage, although the exclusion of a strongly positive study would have suggested no benefit. ${ }^{228} \mathrm{~A}$ recent updated meta-analysis including recent randomised trials, suggests a small survival advantage with an odds ratio for death in the treated group of 0.80 (95\% CI 0.67-0.97) and a relative risk of $0.94(0.88-1.01) .{ }^{229}$ None the less, there remains insufficient evidence to indicate that adjuvant chemotherapy is standard treatment and inclusion of these patients in clinical trials should continue, particularly with more effective drug regimens.

\section{Adjuvant intraperitoneal chemotherapy}

A small randomised study reported improved survival after intraperitoneal administration of mitomycin C absorbed activated charcoal after gastrectomy in T3/4 tumours. ${ }^{230}$ However, when repeated in a randomised multicentre trial this result was not reproduced. ${ }^{231}$ Intraperitoneal chemotherapy (cisplatin/5-FU) may alter the intraperitoneal failure pattern and this may enhance outcome after preoperative systemic chemotherapy. In a non-randomised trial, intraperitoneal chemotherapy post resection following neoadjuvant chemotherapy decreased recurrence rates and improved survival compared with controls. ${ }^{232}$ Similar results have been reported in a randomised study with the effect most marked in stage III cancers. ${ }^{233}$ This approach requires further evaluation and remains investigational.

\section{Neoadjuvant chemotherapy}

Although a number of non-randomised studies have suggested a benefit with improved survival compared with historical controls, ${ }^{234-237}$ randomised trial evidence is not supportive. A Korean randomised trial comparing preoperative cisplatinum, etoposide, and 5-FU with surgery alone failed to show a survival benefit although resectability was improved ${ }^{238}$ A recently reported randomised study of preoperative FAMTX (5 FU, adriamycin, and methotrexate) compared with surgery alone in 56 patients found no benefit with chemotherapy. ${ }^{239}$

Ongoing randomised studies with more effective regimens need to be completed to define the role of neoadjuvant chemotherapy.

\section{Adjuvant chemoradiotherapy}

The role of postoperative chemoradiotherapy in gastric cancer has recently been evaluated in a randomised trial involving 603 patients. ${ }^{240}$ At 3.3 years median follow up there was a disease free and overall survival advantage for the treated group. This approach needs further evaluation to determine whether this early benefit is durable.

\section{PALLIATIVE TREATMENT}

The high proportion of patients presenting with advanced disease highlights the fundamental importance of palliative 
treatment in oesophageal and gastric cancer. Such a principle equally applies to patients with otherwise operable disease who are either unsuitable or unfit for radical intervention. These patients require as careful consideration by the specialist multidisciplinary team as those with potentially curable disease. Furthermore, close liaison between primary and secondary care is essential bearing in mind the short duration of life expectancy after diagnosis.

\section{Palliative chemotherapy and radiotherapy Oesophageal cancer}

Dysphagia is the predominant symptom in advanced oesophageal carcinoma, and the principal goal of palliation is restoration of swallowing. Such a benefit has been shown to correlate strongly with quality of life. ${ }^{241}$ A variety of means may be employed to achieve this goal. Given the short lifespan following treatment, it is important that the chosen method provides rapid resolution of symptoms with minimum disruption to the patient's life and as prolonged a duration of symptom control as possible. The choice of treatment must be tailored to the individual, and will depend on the site, length, and appearance of the tumour, as well as the physical condition of the patient.

\section{Chemoradiation for locally advanced disease}

Randomised trials comparing chemoradiation with radiotherapy alone have shown a benefit in terms of response rate and survival for the combined modality arm. In the Radiation Therapy Oncology Treatment Group study, 129 patients were randomised to receive chemoradiation or radiotherapy only. Complete response rates were reported as $73 \%$ in the combined modality group and $60 \%$ in the radiotherapy alone group. Median survival was also significantly improved ( $12.5 \mathrm{v}$ 8.9 months; $p=0.009) .{ }^{242}$ The interim results of a trial comparing radiotherapy alone with chemoradiation reported that median survival was significantly improved in the chemoradiation arm ( $14.9 v 9.0$ months; $\mathrm{p}=0.03)$.

\section{Palliative chemotherapy}

In advanced oesophageal ACA, palliative chemotherapy has the same benefit as in advanced tumours of the oesophagogastric junction or stomach. ${ }^{243244}$ Regimens used frequently include cisplatin and 5-FU. ${ }^{245}$ Addition of epirubicin may improve the palliative benefit ${ }^{246}$ with a reduction in repeat laser requirements. ${ }^{247} \mathrm{~A}$ similar benefit is achievable in squamous carcinoma. ${ }^{246}$

Early results with paclitaxel, which is also a radiosensitiser, show response rates of $48-70 \%$ in combination with cisplatin, with or without 5-FU, including 12-23\% complete response. ${ }^{248} 249$ Such responses are similar irrespective of tumour type. The use of paclitaxel should remain in the setting of clinical trials and further results, including survival and quality of life figures, are awaited.

\section{Palliative radiotherapy or chemotherapy as stand alone treatment}

Palliative radiotherapy improves dysphagia in 50-85\% of patients and pain is also significantly lessened. The time to onset of improvement however is slow ${ }^{250}$ and improvement is more likely in patients with milder dysphagia. ${ }^{251}$ In a retrospective analysis of 140 patients who received radiotherapy, chemotherapy, or a stent, median time to improvement in symptoms was two months after radiotherapy, variable but prolonged after chemotherapy, and immediate after stent insertion. ${ }^{252}$ Addition of brachytherapy to external beam radiotherapy induces more rapid relief of dysphagia but with a risk of serious side effects including fistula formation. ${ }^{253}$ It is also slower and less successful than either intubation or laser therapy.
Gastric and oesophagogastric junction cancer First line palliative chemotherapy

Careful patient selection is important as those with good performance status and no comorbid disease are more likely to benefit from more aggressive treatment. There are now three randomised studies of chemotherapy compared with best supportive care that show a significant survival and quality of life benefit with chemotherapy. ${ }^{254-256}$ The preferred combination is epirubicin, cisplatin, and continuous infusion of 5-FU (ECF), which has a $65 \%$ response rate including $11 \%$ complete responses. ${ }^{257}$ In a randomised comparison of ECF with FAMTX, ECF was shown to have superior response $(45 \% \mathrm{v}$ $21 \% ; \mathrm{p}=0.0002)$ and survival $(8.9 v 5.7$ months; $\mathrm{p}=0.0009) .{ }^{254}$ Furthermore, ECF had a significantly greater two year survival $(13.5 \%$ v 5.4\%; $\mathrm{p}=0.03) .{ }^{258}$ Substitution of epirubicin by mitomycin $\mathrm{C}$ has shown similar response rates and survival, although ECF appears preferable on quality of life measures. ${ }^{243}$

Paclitaxel is currently being evaluated and combination with $\mathrm{CF}$ has a $51 \%$ response in advanced gastric cancer, with $10 \%$ complete responses. ${ }^{259}$

\section{Second line palliative chemotherapy}

A number of phase I and II studies have demonstrated responses to new combinations following failure of first line chemotherapy. A combination of docetaxel and epirubicin for patients relapsing after 5 -FU/cisplatin was reported as having a $21 \%$ response rate, $30 \%$ stable disease, and symptomatic improvement in 56\%. Median survival was 5.7 months. ${ }^{260}$ Two phase II studies of irenotecan, which included previously treated patients, also indicated sensitivity in this setting. ${ }^{261} 262$

Chemotherapy to downstage locally advanced disease for surgery

In a trial of ECF versus FAMTX, complete surgical resection was rendered possible in 10 of 43 patients with locally advanced disease treated with ECF; three had a pathological complete response. ${ }^{258}$ In a series of 30 patients with stage IIIA, IIIB, or IV gastric cancer treated with neoadjuvant etoposide, doxorubicin, and cisplatin, multivariate analysis showed that complete clinical response to chemotherapy $(n=8 ; p<0.01)$ and complete tumour resection $(\mathrm{n}=24 ; \mathrm{p}<0.01)$ were the major independent predictors of long term survival. ${ }^{234}$

\section{Endoscopic methods}

\section{Oesophageal dilatation}

Improvement in dysphagia has been demonstrated in up to $70 \%$ of patients where a guide wire could be passed. ${ }^{263}$

The incidence of complications, including haemorrhage and perforation, is $2.5-10 \% .{ }^{264} 265$ Different types of dilator have not been compared in randomised controlled trials and reported success and complication rates with balloon, Maloney, and Savary-Gillard dilators are similar. ${ }^{265}$

Recurrence of dysphagia occurred in a mean of 11.5 days in one case series ${ }^{263}$ while Lundell and colleagues ${ }^{265}$ reported that the procedure had to be repeated at intervals of four weeks. As a result, most clinicians reserve dilatation for patients with an extremely short life expectancy.

\section{Injection therapy}

Intratumoral injection of absolute alcohol is of value in soft exophytic tumours and tumours situated too close to the cricopharyngeus for intubation. In nine case series (total 154 patients) a success rate of $80-100 \%$ for relief of dysphagia has been reported. ${ }^{266-272}$ Injection therapy may also be used to control haemorrhage from bleeding tumours. ${ }^{273}$

Mediastinitis and tracheoesophageal fistula have been described in up to $2 \%$ of cases, particularly when larger doses of sclerosant are used. ${ }^{271}$ Postprocedure pain, ${ }^{266} 271$ oesophageal ulceration, ${ }^{268}$ and transient atrial fibrillation ${ }^{267}$ have also been reported. 
Recurrent dysphagia required the procedure to be repeated between $28^{270}$ and 50 days. ${ }^{274}$ This recurrence rate, combined with the need for several initial sessions, results in the recommendation to reserve the use of injection therapy for tumours unsuitable for intubation.

\section{Oesophageal intubation}

Oesophageal intubation is an effective means of relieving dysphagia in a single procedure. Rigid and semirigid plastic tubes (Atkinson, Celestin, Wilson-Cook) are less expensive than self expanding metal stents (Gianturco Z-stent, Wallstent, Ultraflex stent, Oesophacoil). Four randomised trials have demonstrated some advantages with the narrow insertion apparatus and wider lumen of the metal stents. Two of these studies used the Gianturco Z-stent, ${ }^{275} 276$ one the Ultraflex stent, ${ }^{277}$ and the other used the Wallstent. ${ }^{278}$ A large multicentre NHS research and development study to examine this further is currently underway.

Improvement in dysphagia in one procedure has been described in $>90 \%$ of cases with both plastic tubes ${ }^{279-283}$ and metal stents. ${ }^{284-292}$ Only a small proportion of patients with plastic tubes are able to eat solids, with the remainder restricted to a liquid or semi solid diet. Between $50 \%$ and $80 \%$ of patients treated with a metal stent have been able to eat solids in some case series. However, three of four prospective randomised trials ${ }^{276-278}$ have shown no significant difference in dysphagia score following plastic or metal stent insertion.

Overall complication rates of $10-15 \%$ for plastic tubes include oesophageal perforation (6-8\%), haemorrhage (3$5 \%)$, and aspiration pneumonia (2-16\%). Procedural mortality of $2-12 \%$ has been demonstrated in different case series.

Oesophageal perforation and life threatening haemorrhage occur in $<1 \%$ and $4 \%$ of patients, respectively, following metal stent insertion. Procedural morbidity and mortality was significantly lower than with a plastic tube in three of four randomised controlled trials. ${ }^{276-278}$ In two of these studies ${ }^{276} 278$ general anaesthesia was used for plastic tube insertion, which may have influenced these results.

Procedural complications with plastic and metal prostheses may be increased by prior radiation and/or chemotherapy. ${ }^{276}$

Three randomised trials $s^{275-277}$ and one retrospective study ${ }^{293}$ demonstrated shorter hospital stay following metal stent insertion, suggesting that the higher cost of these treatments could be offset.

Comparisons of metal and plastic tubes have not shown any differences in long term complication and re-intervention rates. Large case series have documented low perforation rates following metal stent insertion of $0-2 \%$ but in addition to early re-intervention noted above, late morbidity occurred in approximately $25 \%$ of patients with both types. ${ }^{276} 291292$

Late morbidity with self expanding metal stents is due to tumour ingrowth through the wire mesh of the stent, tumour overgrowth at the ends of the stent, stent migration, food bolus obstruction, haemorrhage, incomplete expansion, and persistent pain.

One randomised trial, using a $22 \mathrm{~mm}$ covered Gianturco metal stent, demonstrated a small survival benefit of metal over plastic prostheses. ${ }^{275}$ This study also found that patients with a metal stent enjoyed their food more than those with a plastic tube, although no overall difference in quality of life was seen in this or other randomised trials of metal versus plastic tubes and plastic tube versus laser. ${ }^{241}$ There are no convincing data to support the use of palliative radiotherapy after insertion of oesophageal stents. It is not known whether metal stents alter the efficacy of radical radiotherapy and it would therefore seem sensible to delay insertion of a metal stent until after radical radiotherapy has been completed if this is envisaged. In cases where a stent is required prior to radical radiation, the use of a plastic stent may be preferable.
Tracheoesophageal fistulation

Several small case series have documented the effectiveness of Wilson-Cook cuffed prostheses ${ }^{294}$ and metal stents in the treatment of tracheoesophageal fistula ${ }^{289}{ }^{295-301}$ and following oesophageal perforation during dilatation of a tumour. ${ }^{302}$ Complete sealing was documented in $87 \%$ of cases.

\section{Oesophageal perforation}

This occurs during tumour dilatation in approximately 2-5\% of procedures. Both cuffed silicone (Wilson Cook) prostheses $^{294}$ and covered metal stents ${ }^{302}$ have been used successfully in this situation with $100 \%$ success and no procedure related mortality.

\section{Combination of radiotherapy and oesophageal intubation}

Although there are no prospective studies combining stents with radiotherapy, there appears to be a role for stent placement in patients with recurrent dysphagia after radiotherapy, particularly in the presence of tight fibrotic strictures. This is usually a late event in the disease. Improved survival after stent insertion has either not been shown in those previously treated with chemotherapy or radiotherapy or is small and with the cost of extra morbidity and prolonged hospital stay. ${ }^{303}$ Several studies have found that previous chemotherapy or radiotherapy increases the risk of specific device related complications to the oesophagus by 3.5. Major complications included haemorrhage, oesophageal perforation, and broncho-oesophageal fistula formation. ${ }^{304-306}$

\section{Gastric outlet obstruction}

Experience with metal stents in the palliation of malignant gastric outlet obstruction is very limited but success has been documented in one case report. ${ }^{307}$

\section{Laser therapy}

Laser as sole modality

Laser therapy is appropriate for tumours with an exophytic component within the oesophageal lumen. This accounts for up to two thirds of all patients. It is contraindicated in patients with broncho-oesophageal fistulae or oesophageal perforation. For lesions crossing the cardia, laser therapy is less successful in providing long term palliation of dysphagia than intubation $^{308}$ although laser therapy prior to insertion of a stent may prevent stent failure. ${ }^{309}$

Recanalisation of the oesophageal lumen is achieved with initial relief of dysphagia in $85-96 \%$ of patients in a mean of two treatment sessions, ${ }^{310-315} 33-36 \%$ of patients are able to tolerate all foods for the duration of their illness, and a further $37-59 \%$ manage solids or semi solids. ${ }^{308} 312316$

The oesophagus is dilated to enable passage of an endoscope and thermal energy is applied in a retrograde fashion commencing at the distal border of the tumour. Oesophageal perforation occurs in $0-5 \%$ of procedures and is often related to pre-laser dilatation. Tracheoesophageal fistula occurs in $0-6 \%$ of cases and is more likely after radiotherapy. The overall 30 day mortality is $0-5 \%{ }^{317}$

The mean dysphagia free interval varies from four to 16 weeks due to regrowth of tumour. ${ }^{312} 315$ Approximately 50\% of patients will be palliated by the initial laser treatment for the duration of their illness. ${ }^{315}$ Recanalisation for tumour regrowth can be successfully achieved with laser as many times as is needed and is more successfully achieved by laser than by dilatation or electrocoagulation. ${ }^{316}$

The complementary use of all modalities results in a better overall quality of swallow than intubation alone. Several studies have found that laser therapy produces better palliation initially reserving intubation for salvage for those with a poor functional result to laser. ${ }^{308} 310318$

Best results occur by individualising the palliative modality to the tumour characteristics and indeed different modalities 
may be appropriate at different stages in the patient's illness. Therefore, palliation is best performed in specialist units which have the full range of palliative modalities.

Most studies show no difference in survival between patients treated with laser or prostheses although a trend to longer survival following laser is seen in some. In two studies comparing patients treated by laser or by insertion of a plastic prosthesis, there was no difference in quality of life between treatments. ${ }^{241319}$

\section{Combination of thermal (Nd:YAG) laser with radiotherapy}

Randomised trials of intubation compared with laser therapy demonstrated a larger number of treatment sessions in those treated by laser. ${ }^{308} 311$ In a terminally ill group, an important aim is to maintain palliation with a minimum of interventions. Studies suggest a prolonged dysphagia free interval in those patients initially treated with laser who go on to receive external beam radiotherapy (30 Gy in 10 fractions). A single brachytherapy treatment ( $10 \mathrm{~Gy}$ ) appears to prolong the dysphagia free interval even more. ${ }^{320-324}$ None of the trials with radiotherapy has shown a survival advantage using combination therapy although trends towards prolonged survival are seen in patients with locally advanced disease only (tumour stage T3N1M0). A small study published in abstract form only did however find a threefold increase in survival in these patients when treated with additional chemoradiotherapy following insertion of a self expanding metal stent. ${ }^{325}$ This area needs further investigation.

Thermal laser therapy for tumours of the cervical oesophagus Tumours involving the cervical oesophagus account for less than $5 \%$ of all patients. ${ }^{326}$ Intubation is not safe within $2 \mathrm{~cm}$ of the upper oesophageal sphincter. Laser therapy or judicious and careful use of oesophageal dilatation is widely held to be the best form of treatment. ${ }^{310}$ Tracheo-oesophageal fistulation is more common for these types of tumour; patients must remain nil by mouth and receive nutrition via a gastrostomy.

Thermal laser for tumour overgrowth or ingrowth through stents Tumour overgrowth at the ends of stents occurs in up to $10 \%$ of patients, particularly those treated with uncovered self expanding metal stents. Recanalisation can be achieved by laser therapy, diathermy, or stent replacement. Placing a second stent across the occluded area is effective although this results in further narrowing of the oesophageal lumen, which will result in a poorer quality final swallow. Nd:YAG laser has been used successfully in many patients in this situation, with stent patency restored after one or two treatment sessions. ${ }^{327}$ Care must be taken not to destroy the stent. As with other laser therapies, these can be done on a day case basis.

\section{Photodynamic therapy and argon plasma coagulation}

Photodynamic therapy (PDT) and argon plasma coagulation (APC) are relatively new techniques which remain unproven. PDT has the disadvantage of skin photosensitisation.

In two randomised controlled trials comparing PDT with conventional Nd:YAG laser, ${ }^{328}{ }^{329}$ relief of dysphagia occurred with improved swallowing after 4-5 days. Tumour regrew in all patients at a similar rate and repeat treatment was needed between one and three months later. Furthermore, all patients treated with PDT had prolonged photosensitivity, which is a significant problem in a palliative setting. These trials must be interpreted cautiously as the duration of palliation using Nd:YAG was shorter than in most other studies.

There are no comparisons of laser and APC and the latter remains an experimental modality. ${ }^{317}$ It may have a role for treatment of tumour overgrowth or ingrowth into metal stents.

\section{FOLLOW UP \\ Introduction}

Follow up of patients with oesophageal and gastric cancer is controversial. The biology of both diseases is such that the majority are on active treatment with the minority attending for symptomatic review.

The aims are:

(1) To detect disorders of function either related to recurrent disease or benign complications of treatment.

(2) To assess and manage nutritional disorders.

(3) To provide psychosocial support for patients and their carers. This includes appropriate medical measures in liaison with palliative care.

(4) To facilitate audit of treatment outcome.

\section{Process}

There is little consensus for the mode, duration, or intensity of follow up in patients with malignant disease. ${ }^{330}$ There is no evidence that intensive follow up improves the speed of detection of recurrent disease in oesophageal or gastric cancers. ${ }^{331-333}$ There is some concern that routine planned hospital appointments may contribute to delay in addressing problems as patients and general practitioners tend to ignore symptoms occurring between outpatient attendances. ${ }^{334}$ Thus outpatient review may not only be ineffective but counterproductive.

The process of follow up should reflect the recommendations of the Calman-Hine ${ }^{335}$ report on the provision of services for those with cancer.

All patients should be systematically followed up according to locally agreed protocols. Follow up could be by the hospital clinic or in primary care and the results of both methods should be subject to audit.

Where follow up is by the hospital clinic it must be multidisciplinary to avoid the duplication of examinations and investigations with incumbent inconvenience to patients and carers.

The first planned follow up examination should be by the multidisciplinary hospital team. Thereafter it could be either at the hospital clinic or in primary care. The patient should be consulted and their wishes respected. A study of patients with various cancers found that the majority were in favour of regular follow up and thought that the advantages outweighed the disadvantages. ${ }^{336}$

General practices undertaking follow up will be those that have expressed a willingness to undertake the work according to locally agreed protocols and to communicate the results to the hospital team. Such practices will be expected to participate in joint audit protocols.

All participating practices should be guaranteed rapid access to specialist services if problems arise.

Patients who are being followed up either at the hospital clinic or in primary care should be able to seek help between review appointments if they are concerned, even if this occurs shortly after a review appointment.

Follow up protocols need to meet the physical and psychological needs of the patient and carers as well as the early detection of recurrent disease.

For individual general practitioners the additional workload is unlikely to be onerous and regularly planned contact should improve the doctor-patient relationship.

Follow up by the general practitioner will not lead to fewer resources being needed at the hospital but could aid the hospital team in reducing waiting times and responding rapidly to requests for help.

There needs to be rapid communication of information between hospital clinic and general practice and vice versa. The ability to achieve this by fax or electronic means should be exploited.

Clinical nurse specialists have a major role in providing continuity of care between primary and secondary care. 
Development of their role should include follow up to reduce the need for medically based review.

Nutritional support for patients is essential after both radical treatment and palliative management and there needs to be ready access for all patients to appropriate dietary advice.

Increasingly, doctors are required to audit their practice and this can be facilitated by multidisciplinary team working. If guidelines are to be of value such teams must audit their results and to achieve this, some form of follow up is essential.

\section{APPENDIX}

\section{Contributors}

Epidemiology and aetiology: D Forman, D Colin-Jones; Diagnosis: M Bramble, MT Hallissey; Staging: J Anderson, A McLean, A Chalmers, K Harris; Pathology: M Bennett, NA Shepherd, N Mapstone; Preoperative assessment: I Shaw; Surgery-Oesophagus: D Alderson, R Vaughan, J A McGuigan; Surgery—Stomach: SA Raimes, H Sue-Ling; Chemotherapy and radiotherapy: D Cunningham, T Price, J Waters; Endoscopic palliation: H Shepherd, CD Roseveare, S Bown, L Lovat, RC Mason; Follow up: J Bancewicz, C Waine.

\section{Authors' affiliations}

W H Allum, Department of Surgery, Epsom Hospital, Dorking Rd, Epsom, Surrey KT18 7EG, UK

S M Griffin, Northern Oesophago-gastric Cancer Unit, Ward 36, Royal Victoria Infirmary, Queen Victoria Rd, Newcastle upon Tyne NE 1 4LP, UK

A Watson, Department of Surgery, Royal Free Hospital, Pond Street, Hampstead, London NW3 2QG, UK

D G Colin-Jones, Queen Alexandra Hospital, Cosham, Portsmouth, Hants PO6 3LY, UK

Correspondence to:

Mrs Chris Romaya, Audit Office, British Society of Gastroenterology, $3 \mathrm{St}$ Andrews Place, Regent's Park, London NW1 4LB;

romaya_bsg@hotmail.com

Accepted for publication

20 November 2001

\section{REFERENCES}

1 Eccles M, Clapp Z, Grimshaw J, et al. North of England evidence based guidelines development project: methods of guideline development. BM 1996:312:760-2.

2 CRC (Cancer Research Campaign). Factsheet 1.1 Incidence-UK. London: Cancer Research Campaign, 1998

3 CRC (Cancer Research Campaign). Cancer Stats Mortality-UK. London: Cancer Research Campaign, 1999

4 Office for National Statistics. Registrations of cancer diagnosed in 1993-96, England and Wales. Health Stat Q 1999;4:59-70.

5 Blot WJ. Esophageal cancer trends and risk factors. Semin Onco 1994;21:403-10.

6 Vaughan TL, Davis S, Kristal A, et al. Obesity, alcohol and tobacco risk factors for cancers of the esophagus and gastric cardia: adenocarcinoma versus squamous cell carcinoma. Cancer Epidemiol Biomarkers Prev 1995;4:85-92.

7 Hu J, Nyren O, Wolk A, et al. Risk factors for oesophageal cancer in northeast China. Int J Cancer 1994:57:38-46.

8 Brown LM, Silverman DT, Pottern LM, et al. Adenocarcinoma of the esophagus and esophagogastric junction in white men in the United States: alcohol, tobacco, and socioeconomic factors. Cancer Causes Control 1994;5:333-40.

9 Rolon PA, Castellsague X, Benz M, et al. Hot and cold mate drinking and esophageal cancer in Paraguay. Cancer Epidemiol Biomarkers Prev 1995;4:595-605.

10 Castelletto R, Castellsague X, Munoz N, et al. Alcohol, tobacco, diet, mate drinking, and esophageal cancer in Argentina. Cancer Epidemiol Biomarkers Prev 1994:3:557-64.

11 Gao YT, McLaughlin JK, Blot W, et al. Risk factors for esophageal cancer in Shanghai, China. I Role of cigarette smoking and alcohol drinking. Int J Cancer 1994;58:192-6.

12 Gao YT, McLaughlin KJ, Gridley G, et al. Risk factors for esophageal cancer in Shanghai, China. II Role of diet and nutrients. Int J Cancer 1994; 58:197-202

13 Tavani A, Negri E, Franceschi S, et al. Risk factors for esophageal cancer in women in northern Italy. Cancer 1993;72:2531-6.

14 Cheng KK, Day NE, Duffy SW, et al. Pickled vegetables in the aetiology of oesophageal cancer in Hong Kong Chinese. Lancet 1992;339:1314-18.
15 Lagergren J, Bergstrom R, Nyren O, et al. Association between body mass and adenocarcinoma of the esophagus and gastric cardia. Ann Int Med 1999; 130:883-90

16 Iftikhar SY, James PD, Steele RJ, et al. Length of Barrett's oesophagus: an important factor in the development of dysplasia and adenocarcinoma. Gut 1992:33:1155-8.

17 Liberman DA, Oehike M, Helfand M. Risk factors for Barrett's oesophagus in community based practice GORGE consortium. Gastroenterology Outcomes Research Group in Endoscopy. Am J Gastroenterol 1997:92:1293-7.

18 Lagergren J, Bergstrom R, Londgren A, et al. Symptomatic gastroesophageal reflux as a risk factor for esophageal adenocarcinoma. N Engl J Med 1999;340:852-31

19 Sandler RS, Nyren O, Ekbom A, et al. The risk of esophageal cancer in patients with achalasia. A population-based study. JAMA 1995; 274:359-62.

20 Loviscek LF, Cenoz MC, Badaloni AE, et al. Early cancer in achalasia. Dis Esophagus 1998;11:239-47.

21 Meijssen MA, Tilanus HW, van Blankenstein M, et al. Achalasia complicated by oesophageal squamous cell carcinoma: a prospective study in 195 patients. Gut 1992;33:155-8

22 Sedgwick DM, Akoh J, Macintyre IMC. Gastric cancer in Scotland: changing epidemiology, unchanging workload. BM 1991;302:1305-7

23 Fielding JW, Ellis DJ, Jones BG, et al. Natural history of "early" gastric cancer: results of a 10-year regional survey. BM 1980;281:965-7.

24 Allum WH, Powell DJ, McConkey CC, et al. Gastric cancer: a 25-year review. Br J Surg 1989;76:535-40.

25 Powell DJ, McConkey CC. The rising trend in oesophagea adenocarcinoma and gastric cardia. Euro J Cancer Prevent $1992 ; 1: 265-9$.

26 Dolan K, Sutton R, Walker SJ, et al. New classification of oesophageal and gastric carcinomas derived from changing patterns in epidemiology. Br J Cancer 1999:80:834-42.

27 Correa P. A human model of gastric carcinogenesis. Cancer Res 1988:48:3554-60.

28 Stockbrugger RW, Menon GG, Beilby JOW, et al. Endoscopic screening in patients with pernicious anaemia. In: Cotton P, ed. Early gastric cancer. Welwyn Garden City: Smith Kline \& French Laboratories, 1982:64-66

29 Stalsberg $\mathbf{H}$, Taksdal S. Stomach cancer following gastric surgery for benign surgical conditions. Lancet 1971;ii:1175-7.

30 Forman D, Newell DG, Fullerton E, et al. Association between infection with Helicobacter pylori and risk of gastric cancer: evidence from a prospective investigation. BM 1991;302:1302-5

31 Parsonnet J, Friedman G, Vandersteen DP, et al. Helicobacter pylori infection and the risk of gastric carcinoma. N Engl J Med 1991;325:1127-31.

32 Kuipers EJ. Review article: exploring the link between Helicobacter pylori and gastric cancer. Aliment Pharmacol Ther 1999;13/suppl 1):3-11.

33 Danesh J. Helicobacter pylori infection and gastric cancer : systematic review of the epidemiological studies. Aliment Pharmacol Ther 1999;13:851-6.

34 Eslick GD, Lim LLY, Byles J, et al. Association of Helicobacter pylori infection with gastric carcinoma: a meta-analysis. Am J Gastroenterol 1999;94:2373-9.

35 Huang JQ, Sridhar S, Chen Y, et al. Meta-analysis of the relationship between Helicobacter pylori seropositivity and gastric cancer. Gastroenterology 1998;114:1169-79.

36 American Institute for Cancer Research. World Cancer Research Fund Food, nutrition and the prevention of cancer: a global perspective. Washington: American Institute for Cancer Research, 1997.

37 Department of Health Report on Health and Social Subjects 48. Nutritional aspects of the development of cancer. London: Her Majesty's Stationery Office, 1998.

38 Munoz N, Vivas J, Buiatti E, et al. Chemoprevention trial of precancerous lesions of the stomach in Venezuela. Eur J Cancer Prevent 1993;2(suppl 1):5.

39 Mowat C, Carswell A, Wirz A, et al. Omeprazole and dietary nitrate independently affect levels of vitamin $\mathrm{C}$ and nitrite in gastric juice. Gastroenterology 1999;116:813-22. (erratum published in Gastroenterology 1999;116:1507)

40 Hill MJ. Salt and gastric cancer. Eur J Cancer Prev 1998;7:173-5.

41 Tredaniel J, Boffetta $P$, Buiatti $E$, et al. Tobacco smoking and gastric cancer: review and meta-analysis. Int J Cancer 1997;72:565-73.

42 Neugut Al, Hayek M, Howe G. Epidemiology of gastric cancer. Semin Oncol 1996;23:281-91.

43 Talley NJ, Weaver AL, Tesmer DL, et al. Lack of discriminant value of dyspepsia subgroups in patients referred for upper endoscopy. Gastroenterology 1993;105:1378-86.

44 Bytzer P, Hansen JM, Havelund T, et al. Predicting endoscopic diagnosis in the dyspeptic patient; the value of clinical judgement. Eur J Gastroenterol Hepatol 1996;8:359-63

45 Jones RH, Lydeard SE, Hobbs FD, et al. Dyspepsia in England and Scotland. Gut 1990;31:401-5

46 Martin IG, Young S, Sue-Ling HM, et al. Delays in the diagnosis of oesophagogastric cancer: a consecutive case series. BM 1997;314:467-71.

47 NHS Executive Referral Guidelines for Suspected Cancer. London: HMSO, 2000.

48 Kohli Y, Kawai K, Fujita S. Analytical studies on growth of human gastric cancer. J Clin Gastroenterol 1981;3:129-33. 
49 Dooley CP, Larson AW, Stace NH, et al. Double contrast barium meal and upper gastrointestinal endoscopy. Ann Intern Med 1984;101:538-45

50 Adachi Y, Kitamura K, Tsutsui S, et al. How to detect early carcinoma of the esophagus. Hepatogastroenterology 1993:40:207-11.

51 Garg PK, Misra MC, Bal S, et al. Foreign body in the esophagus mimicking esophageal carcinoma. Am J Gastroenterol 1996;91:397-8.

52 Msika S, Tazi MA, Benhamiche AM, et al. Population-based study of diagnosis treatment and prognosis of gastric cancer. Br J Surg 1997:84:1474-8.

53 Sue-Ling HM, Johnson D, Martin IG, et al. Gastric cancer: a curable disease in Britain. BM 1993;307:591-6.

54 Suvakovic Z, Bramble MG, Jones R, et al. Improving the detection rate of early gastric cancer requires more than open gastroscopy. A five yea study. Gut 1997;41:308-13.

55 Wilkins WE, Walker J, McNulty MR, et al. The organisation and evaluation of an open access dysphagia clinic. Ann R Coll Surg Engl 1984;66:115-16.

56 Lambert R. Palliation of carcinoma of the esophagus. Is there a hope of cure? Am J Gastroenterol 1994;89:S27-40.

57 Hallissey MT, Allum WH, Jewkes AN, et al. Early detection of gastric cancer. BM 1990;301:513-15.

58 Eckardt VF, Giebler W, Kanzler G, et al. Clinical and morphological characteristics of early gastric cancer. Gastroenterology 1990;98:708-14.

59 Fuchs CS, Mayer RJ. Gastric carcinoma. N Engl J Med 1995;333:32-41.

60 Johannessen T, Peterson H, Kleveland PM, et al. The predictive value of history in dyspepsia. Scand J Gastroenterol 1990;25:689-97.

61 Bytzer P, Moller-Hansen J, Havelund T, et al. Predicting endoscopic diagnosis in the dyspeptic patient: the value of predictive score models. Scand J Gastroenterol 1997;32:1 18-25.

62 Talley NJ, Silverstein MD, Agreus L, et al. AGA technical review: evaluation of dyspepsia. Gastroenterology 1998; 1 14:582-95.

63 Bramble MG, Suvakovic Z, Hungin APS. Detection of upper gastrointestinal cancer in patients taking antisecretory therapy. Gut 2000;46:464-7

64 Wayman J, Hayes N, Griffin SM. Response of early gastric cancer to proton pump inhibitors. N Engl J Med 1998;338:1924-5

65 Glaws WR, Etzkom KP, Wenig BL, et al. Comparison of rigid and flexible esophagoscopy in the diagnosis of esophageal disease: diagnostic accuracy, complications and cost. Ann Otol Rhinol Laryngol 1996; 105:262-6.

66 Boyce GA. Endoscopic evaluation of the patient with esophageal carcinoma. Chest Surg Clin North Am 1994;4:257-68.

67 Delvaux M, Korman LY. Minimal standard terminology. Endoscopy 2000;32:159-88.

68 Levine DS, Haggitt RC, Blount PL, et al. An endoscopic biopsy protocol can differentiate high-grade dysplasia from early adenocarcinoma in Barrett's esophagus. Gastroenterology 1993;105:40-50.

69 Spechler SJ, Zeroogian JM, Antonioli DA, et al. Prevalence of metaplasia at the gastroesophageal junction. Lancet 1994;344:1533-6.

70 Falk GW, Rice TW, Goldblum JR, et al. Jumbo forceps protocol stil misses unsuspected cancer in Barrett's oesophagus with high-grade dysplasia. Gastrointest Endosc 1999;49:170-6.

71 Macdonald CE, Wicks AC, Playford RJ. Final results from 10 year cohort of patients undergoing surveillance for Barrett's oesophagus: observational study. BN 2000;321:1252-5

72 Lal N, Bhasin DK, Malik AK, et al. Optimal number of biopsy specimens in the diagnosis of carcinoma of the oesophagus. Gut 1992;33:724-6.

73 Sobin LH, Wittekind Ch, eds. TNM classification of malignant tumours, 5th edn. New York: Wiley-Liss, 1997

74 Saunders HS, Wolfman NT, OH DJ. Oesophageal cancer: radiological staging. Radiol Clin North Am 1997;35:281-94.

75 Takahima S, Takeuchi N, Shiozaki H, et al. Carcinoma of the esophagus: CT vs MR imaging in determining resectability. Am J Roentgenol 1991;156:297-302

76 Ziegler K, Sanft C, Friedrich M, et al. Evaluation of endosonography in TN staging of oesophageal cancer. Gut 1991;32:16-20.

77 Consigliere D, Chua C I L, Hui F, et al. Computed tomography in the pre-operative evaluation of resectability and staging in oesophageal carcinoma. Eur J Surg 1992;158:537-40.

78 van Overhagen $\mathbf{H}$, Lameris JS, Berger MY, et al. Improved assessment of supraclavicular and abdominal metastases in oesophageal and gastro-oesophageal junction carcinoma with the combination of ultrasound and computed tomography. Br J Radiol 1993;66:203-8.

79 Greenberg J, Durkin $M$, van Drunen $M$, et al. Computed tomography or endoscopic ultrasonography in preoperative staging of gastric and esophageal tumours. Surgery 1994;116:797-802.

80 Minami M, Kawauchi N, Itai Y, et al. Gastric Tumours : Radiologicpathologic Correlation and Accuracy of T Staging with Dynamic CT. Radiology 1992;185: 173-8.

81 Cho JS, Kim JK, Rho SM, et al. Pre-operative assessment of gastric carcinoma: value of two-phase dynamic CT with mechanical IV injection of contrast material. Am J Roentgenol 1994;163:69-75.

82 Davies J, Chalmers AG, Sue-Ling HM, et al. Spiral computed tomography and operative staging of gastric carcinoima: a comparison with histopathological staging. Gut 1997;42:314-9

83 Van Overhagen $\mathbf{H}$, Lameris JS, Berger MY, et al. CT assessment of resectability prior to transhiatal oesophagectomy or oesophageal/ gastro-oesophageal junction carcinoma. Comput Assist Tomogr 1993;17:367-73.
84 Fukuya T, Honda $\mathrm{H}$, Kaneko $\mathrm{K}$, et al. Efficacy of helical CT in T-staging of gastric cancer. J Comput Assist Tomogr 1997;21:73-81.

85 Tio TL, Cohen P, Coene PP, et al. Endosonography and computed tomography of esophageal carcinoma. Preoperative classification compared to the new (1987) TNM system. Gastroenterology 1989:96:1478-86

86 Dittler HJ, Siewart JR. Role of endoscopic ultrasonography in esophageal carcinoma. Endoscopy 1993;25:156-61.

87 Vilgrain V, Mompoint D, Palazzo L, et al. Staging of esophagea carcinoma: Comparison of results with endoscopic sonography and $\mathrm{CT}$. Am J Roentgenol 1990;155:277-81.

88 Botet JF, Lightdale CJ, Zauber AG, et al. Preoperative staging of esophageal cancer: Comparison of endoscopic US and dynamic CT. Radiology 1991;181:419-25.

89 Hordijk ML, Zander $\mathrm{H}$, van Blankenstein $M$, et al. Influence of tumour stenosis on the accuracy of endosonography in preoperative T staging of oesophageal cancer. Endoscopy 1993;25:171-5.

90 Binmoeller KF, Seifert H, Seitz U, et al. Ultrasonic esophagoprobe for TNM staging of highly stenosing esophageal carcinoma. Gastrointest Endosc 1995;41:547-52

91 Ziegler K, Sanft C, Zimmer T, et al. Comparison of computed fomography, endosonography and intraoperative assessment in TN staging of gastric carcinoma. Gut 1993:34:604-10.

92 Catalano MF, Sivak MV, Rice T, et al. Endosonographic features predictive of lymph node metastasis. Gastointest Endosc 1994;40:442-6.

93 Grimm H, Binmoeller KF, Hamper K, et al. Endosonography for preoperative locoregional staging of esophageal and gastric cancer Endoscopy 1993:25:224-30.

94 Catalano MF, Alcocer E, Chak A, et al. Evaluation of metastatic celiac axis lymph nodes in patients with esophageal carcinoma: accuracy of EUS. Gastointest Endosc 1999;50:352-6.

95 Bhutani MS, Hawes RH, Hoffman BJ. A comparison of the accuracy of echo features during endoscopic ultrasound (EUS) and EUS-guided fine needle aspiration for diagnosis of malignant lymph node invasion. Gastointest Endosc 1997:45:474-9.

96 Harris KM, Kelly S, Berry E, et al. Systematic review of endoscopic ultrasound in gastro-oesophageal cancer. Health Technol Assess 1998;2:18.

97 Quint LE, Hepburn LM, Francis IR, et al. Incidence and distribution of distant metastases from newly diagnosed esophageal carcinoma. Cancer 1995; $76: 1120-5$

98 Kuszyk BS, Bluemke DA, Urban BA, et al. Portal phase contrast enhanced helical CT for the detection of malignant hepatic tumours: sensitivity based on comparison with intraoperative and pathologic findings. Am J Roentgenol 1996;166:91-5.

99 Jones EC, Chezmar J, Nelson RC, et al. The frequency and significance of small $(<15 \mathrm{~mm})$ hepatic lesions detected by CT. Am J Roentgenol 1992; 158:535-9

100 Schwartz LH, Gandras EJ, Colangelo SM, et al. Prevalence and importance of small hepatic lesions found at CT in patients with cancer. Radiology 1999;210:71-4.

101 Royal College of Radiologists. Making the best use of Department of Clinical Radiology, 4th edn. London: RCR, 1998

102 Takashima S, Takeuchi N, Shiozaki H, et al. Carcinoma of the esophagus: CT vs MR imaging in determining resectability. Am J Radiol 1991;156:297-302.

103 Matsushita M Hiromichi O, Murakami T, et al. Extraserosal invasion in advanced gastric cancer: evaluation with MR imaging. Radiology 1994;192:87-91.

104 Hagspiel KD, Neidle KFW, Eichenberger AC, et al. Detection of liver metastases: comparison of superparamagnetic iron oxide-enhanced and unenhanced MR imaging at $1.5 \mathrm{~T}$ with dynamic CT, intra-operative US and percutaneous US. Radiology 1995; 196:471-8.

105 Stell DA, Carter CR, Stewart I, et al. Prospective comparison of laparoscopy, ultrasonography and computed tomography in the staging of gastric cancer. Br J Surg 1996;83:1260-2.

106 Molloy RG, McCourtney JS, Anderson JR. Laparoscopy in the management of patients with cancer of the gastric cardia and oesphagus. Br J Surg 1995:82:352-4.

107 Hunerbein M, Rau B, Schalg PM. Laparoscopy and Laparoscopic Ultrasound for Staging of Upper Gastrointestinal Tumours. Eur J Surg Oncol 1995;21:50-5

108 Miros M, Kerlin P, et al. Only patients with dysplasia progress to adenocarcinoma in Barrett's oesophagus. Gut 1991:32:1441-6.

109 Tytgat GNJ. Endoscopic features of columnar-lined esophagus. Gastroenterol Clin N Am 1997;26:507-17.

110 Paraf F, Flejou JF, Pignon JP, et al. Surgical pathology of adenocarcinoma arising in Barrett's esophagus. Analysis of 67 cases. Am J Surg Pathol 1995; 19:183-91.

111 Mapstone N. Minimum dataset for oesophageal carcinoma histopathology reports. London: The Royal College of Pathologists, 1998

112 Sagar PM, Johnston D, McMahon M, et al. Significance of circumferential resection margin involvement after oesophagectomy for cancer. Br J Surg 1993;80:1386-8.

113 Tsutsui S, Kuwano H, Watanabe M, et al. Resection margin for squamous-cell carcinoma of the esophagus. Ann Surg 1995;222: 193-202.

114 Rokkas T, Filipe MI, Sladen GE. Detection of an increased incidence of early gastric cancer in patients with intestinal metaplasia type III who are closely followed up. Gut 1991;32:1110-13.

115 Goldstein NS, Lewin KJ. Gastric epithelial dysplasia and adenoma: historical review and histological criteria for grading. Hum Pathol 1997; 28:127-33 
116 Lansdown M, Quirke P, Dixon MF, et al. High grade dysplasia of the gastric mucosa: a marker for gastric carcinoma. Gut 1990;31:977-83.

117 Japanese Research Society for Gastric Cancer. Japanese classification of gastric cancer, 1 st English edn. Tokyo: Kanehara \& Co Ltd, 1995

118 Kaiiyama V, Tsurumaru $M$, Udagawa $H$, et al. Prognostic factors in adenocarcinoma of the gastric cardia: pathologic stage analysis and multivariate analysis. J Clin Oncol 1997;15:2015-21.

119 Baba JD, Okuyama T, Hiroyuki O, et al. Prognostic factors for non-curative gastric cancer: univariate and multivariate analyses. J Surg Oncol 1992:51:104-8

120 Mori M, Adachi Y, Kamakura T, et al. Neural invasion in gastric carcinoma. J Clin Pathol 1995;48:137-42.

121 Jakl RJ, Miholic J, Koller R, et al. Prognostic factors in adenocarcinoma of the cardia. Am J Surg 1995;169:316-19.

122 Japanese Society for Esophageal Diseases. Guidelines for the clinical and pathologic studies on carcinoma of the esophagus. Jpn J Surg 1976:6:69-78

123 Compton C, Sobin LH. Protocol for the examination of specimens removed from patients with gastric carcinoma: a basis for checklists. Arch Pathol Lab Med 1998:122:9-14.

124 Siewert JR, Stein HJ. Adenocarcinoma of the gastro-oesophagea junction. Classification, pathology and extent of resection. Dis Esophagus 1996;9:173-82

125 Aikou T, Shimazu H. Difference in main lymphatic pathways from the lower esophagus and gastric cardia. Jpn J Surg 1989;19: 290-5.

126 Prytherch DR, Whitley B, Higgins B, et al. POSSUM and Portsmouth POSSUM for predicting mortality. Br J Surg 1998;85:1217-20.

127 Goldman L, Debra MPH, Caldera RN, et al. Multifactorial index of cardiac risk in noncardiac surgical procedures. N Engl J Med 1977;297:845-50.

128 Goldman L, Caldera DL Risks of general anaesthesia and elective operation in the hypertensive patient. Anesthesiology 1979;50:285-90.

129 Goldman L. Assessment of perioperative cardiac risk. N Engl J Med 1994;330:707-9.

130 Gray AJG, Hoile RW, Ingram GS, et al, eds. The Report of the Nationa Confidential Enquiry into Perioperative Deaths 1996/97. London: CEPOD, 1999

131 Curran JE, Grounds RM. Ward versus intensive care management of high risk surgical patients. Br J Surg 1998;85:956-61.

132 Campling EA, Devlin HB, Hoile RW, et al, eds. The Report of the National Confidential Enquiry into Perioperative Deaths 1990. London: CEPOD, 1992

133 Detsky AS, Abrams HB, McLauchlin JR. Predicting cardiac complications in patients undergoing non-cardiac surgery. J Gen Int Med 1986;41:211-19.

134 Wong DH, Weber EC, Schell M, et al. Factors associated with postoperative pulmonary complications in patients with severe chronic obstructive pulmonary disease. Anesth Analg 1995;80:276-84.

135 Fan ST, Lau WY, Yip WC, et al. Prediction of postoperative pulmonary complications in oesophagogastric surgery. Br J Surg 1987:74:408-10.

136 Campling EA, Devlin HB, Hoile RW, et al, eds. The Report of the National Confidential Enquiry into Perioperative Deaths 1992/93. London: CEPOD, 1995

137 Erskine RJ, Hanning CD. Do I advise my patient to stop smoking preoperatively? Curr Anaesth Crit Care 1992;3:175-80.

138 Smith TP, Kinasewitz GT, Tucker WY, et al. Exercise capacity as a predictor of post thoracotomy morbidity. Am Rev Respir Dis 1984; 129:730-4.

139 Ninan M, Sommers KE, Landreneua RJ, et al. Standardised exercise oximetry predicts post pneumonectomy outcome. Ann Thorac Surg 1997:64:328-33

140 Carliner HN, Fisher ML, Plotnick GD, et al Routine preoperative exercise testing in patients undergoing major non-cardiac surgery. Am J Surg 1985;56:51-8

141 Mangano DT. Preoperative assessment of the patient with cardiac disease. Baillieres Clin Anaesth 1989;3:47-102.

142 Juste RN, Lawson AD, Soni N. Minimising cardiac anaesthetic risk. Anaesthesia 1996;51:255-62.

143 Dick WF. Preoperative screening for elective surgery. Baillieres Clin Anaesth 1998:12:349-71.

144 Nunn JF, Milledge JS, Chen D, et al. Respiratory criteria of fitness for surgery and anaesthesia. Anaesthesia 1988;43:543-51

145 Entwhistle MD, Roe PG, Sapsford DJ, et al. Patterns of oxygenation after thoracotomy Br J Anaesth 1991:67:704-11.

146 Nagawa H, Kobori O, Mutto T. Prediction of pulmonary complications after transthoracic oesophagectomy. Br J Surg 1994;81:860-2

147 Shenkman Z, Shir Y, Brodsky JB. Perioperative management of the obese patient. Br J Anaesth 1993;70:349-59.

148 Blazeby JM, Farndon JR, Donovan J, et al. A prospective longitudinal study examining the quality of life of patients with oesophageal carcinoma. Cancer 2000;88:1781-7.

149 Low molecular weight heparins for venous thromboembolism. Drug Ther Bull 1998;36:25-9.

150 Dresner SM, Lamb PJ, Shenfine J, et al. Prognostic significance of peri-operative blood transfusion following radical resection for oesophageal carcinoma. Eur J Surg Oncol 2000;26:492-7.

151 Müller JM, Erasmi H, Stelzner M, et al. Surgical therapy of oesophageal carcinoma. Br J Surg 1990;77:845-57.

152 Bonavina L. Early oesophageal cancer: results of a European multicentre survey. Group Europeen pour L'Etude des Maladies de L'Oesophage. $\mathrm{Br}$ J Surg 1995;82:98-101.
153 Hölscher $\mathbf{A H}$, Bollschweiler E, Schneider PM, et al. Early adenocarcinoma in Barrett's oesophagus. Br J Surg 1997;84:1470-3.

154 Lerut T, Deleyn P, Coosemans W, et al. Surgical strategies in oesophageal carcinoma with emphasis on radical lymphadenectomy. Ann Surg 1994;216:583-90.

155 Bartels H, Stein HJ, Siewert JR. Preoperative risk analysis and postoperative mortality of oesophagectomy for resectable oesophageal cancer. Br J Surg 1998;85:840-4

156 Matthews HR, Powell DJ, McConkey CC. Effect of surgical experience on the results of resection for oesophageal cancer. Br J Surg 1986;72:621-8.

157 Ellis FH Jr, Jackson RC, Krueger JT Jr, et al. Carcinoma of the esophagus and cardia: results of treatment, 1946 to 1956. N Engl J Med 1959;260:351-8

158 Ellis FH Jr. Treatment of carcinoma of the esophagus or cardia. Mayo Clin Proc 1989:64:945-55.

159 Skinner DB. En bloc resection for neoplasms of the esophagus and cardia. J Thorac Cardiovasc Surg 1983;85:59-71.

160 Skinner DB, Little AG, Ferguson MK, et al. Selection of operation for esophageal cancer based on staging. Ann Surg 1986;204:391-401.

161 Sugimachi K, Watanabe M, Sadanaga N, et al. Recent advances in the diagnosis and surgical treatment of patients with carcinoma of the esophagus. J Am Coll Surg 1994;178:363-8.

162 Giuli R. Surgical complications and reasons for failure. In: DeMeester TR, Leven B, eds. Cancer of the oesophagus. Orlando: Brune \& Stratton, 1985:199-208.

163 Miller C. Carcinoma of the thoracic oesophagus and cardia; a review of 405 cases. Br J Surg 1962:49:507-10.

164 Giuli R, Sancho-Garnier H. Diagnostic, therapeutic and prognostic features of cancers of the esophagus: results of the international prospective study conducted by the OESO group. Surgery 1986;5:614-22

165 Wong J. Methods available to assess the quality of surgical resection. In: Giuli R, ed. Proceedings of the First Polydisciplinary International Congress OESO. Paris: Ed Maloine SA, 1984.

166 Tam PC, Sui KF, Cheung HC, et al. Local recurrences after sub-total oesophagectomy for squamous cell carcinoma. Ann Surg 1987;205: 189-94.

167 Sons HU, Borchard F. Cancer of the distal oesophagus and cardia Incidence, tumourous infiltration and metastatic spread. Ann Surg 1986;203: 188-95

168 Alderson D, Courtney SP, Kennedy RH. Radical transhiatal oesophagectomy under direct vision. Br J Surg 1994;81:404-7.

169 Roder JD, Busch R, Stein JH, et al. Ratio of invaded to removed lymph nodes as a predictor of survival in squamous cell carcinoma of the oesophagus. Br J Surg 1994;81:410-13

170 Akiyama $\mathbf{H}$, Tsurumaru M, Udagawa $H$, et al. Radical lymph node dissection for cancer of the thoracic oesophagus. Ann Surg 1994;220:364-73.

171 Siewert JR, Roder JD. Lymphadenectomy in oesophageal cancer surgery. Dis Esophagus 1992;2:91-7.

172 Hölscher $\mathbf{A H}$, Voite H, Buttermann $\mathbf{G}$, et al. Function of the intrathoracic stomach as esophageal replacement. World J Surg 1988;12:835-44.

173 Cheung HC, Cusiu KF, Wong J. Is pyloroplasty necessary in oesophageal replacement by stomach? A prospective randomised controlled trial. Surgery 1997;102:19-24.

174 DeMeester TR, Johansson KE, Franze I, et al. Indications, surgical echnique and long-term functional results of colon interposition or bypass. Ann Surg 1988;208:460-74.

175 Bartels H, Thorban S, Siewert JR. Anterior versus posterior reconstruction after transhiatal oesophagectomy: a randomised controlled trial. $\mathrm{Br} J$ Surg 1993;80:1141-4.

176 Van Lanschott JJB, van Blankenstein M, Oeiss HY, et al. Randomised comparison of prevertebral and retrosternal gastric tube reconstruction after resection of oesophageal carcinoma. Br J Surg 1999:86:102-8.

177 Fok M, Ah-Chong AK, Cheng SW, et al. Comparison of a single layer continuous hand-sewn method and circular stapling in 580 oesophagea anastomoses Br J Surg $1991 ; 78: 342-5$

178 Valverde A, Hay JM, Fingerhut $A$, et al. Manual versus mechanical esophagogastric anastomosis after resection for carcinoma: a controlled trial. Surgery 1996;120:476-83.

179 Zieren HU, Müller JM, Pichlmaier H. Prospective randomized study of one- or two-layer anastomosis following oesophageal resection and cervical oesophagogastrostomy. Br J Surg 1993;80:608-1 1.

180 Wakefield SE, Mansell NJ, Baigrie RJ, et al. Use of a feeding jejunostomy after oesophagogastric surgery. Br J Surg 1995;82:81 1-13.

181 Fan ST, Lau WY, Yip WC, et al. Prediction of post-operative pulmonary complications in oesophagogastric cancer surgery. Br J Surg 1987;74:408-10.

182 Nagawa H, Kobori O, Muto T. Prediction of pulmonary complications after transthoracic oesophagectomy. Br J Surg 1994:81:860-2.

183 Watson A. Operable esophageal cancer: current results from the West. World J Surg 1994;18:361-7

184 Watson A, Allen PR. Influence of thoracic epidural analgesia on outcome after resection for oesophageal cancer. Surgery 1994;115:429-32.

185 Vigneswaran WT, Trastek VF, Pairolero PC, et al. Transhiatal esophagectomy for carcinoma of the esophagus. Ann Thorac Surg 1993;56:838-46.

186 Sauvanet A, Baltar J, Le Mee J, et al. Diagnosis and conservative management of intrathoracic leakage after oesophagectomy. Br J Surg 1998;85: 1446-9.

187 Paterson IM, Wong J. Anastomotic leakage: an avoidable complication of Lewis-Tanner esophagectomy. Br J Surg 1989;76:127-9. 
188 Lam TC, Fok M, Cheng SW, et al. Anastomotic complications after esophagectomy for cancer. A comparison of neck and chest anastomoses. J Thorac Cardiovasc Surg 1992;104:395-400.

189 Bolger C, Walsh TN, Tanner WA, et al. Chylothorax after oesophagectomy. Br J Surg 1991;78:587-8.

190 Douganis D, Walker WS, Cameron EW, et al. Management of chylothorax complicating extensive esophageal resection. Surg Gynecol Obstet 1992;174:501-6.

191 Dugue L, Sauvanet A, Farges $O$, et al. Output of chyle as an indicator of treatment for chylothorax complicating oesophagectomy. Br J Surg 1998;85:1147-9.

192 Orringer MB, Bluett M, Deeb GM. Aggressive treatment of chylothorax complicating transhiatal esophagectomy without thoracotomy. Surgery 1988;104:720-6.

193 Griffin SM, Chung SCS, Van Hasselt CA, et al. Late swallowing problems after oesophagectomy for cancer. Malignant infiltration of the recurrent laryngeal nerves and its management. Surgery 1992;112:533-5.

194 Orringer MB. Transhiatal oesophagectomy without thoracotomy for carcinoma of the thoracic oesophagus. Ann Surg 1984;200:282-8.

195 Finley RJ, Inculet RI. The results of esophagogastrectomy without thoracotomy for adenocarcinoma of the esophagogastric junction. Ann Surg 1989;210:535-43

196 Dresner SM, Lamb PJ, Wayman J, et al. Benign anastomotic stricture following transthoracic subtotal oesophagectomy and stapled oesophago-gastrostomy: risk factors and management. Br J Surg 2000;87:370-1.

197 Pierie JPEN, de Graaf PW, Poen H, et al. Incidence and management of benign anastomotic stricture after cervical oesophagogastrostomy. $\mathrm{Br} J$ Surg 1993;80:471-4

198 Akoh JA, Macintyre IMC. Improving survival in gastric cancer: a review of 5-year survival rates in English language publications from 1970. Br Surg 1992;79:293-9.

199 Cuschieri A, Fayers P, Fielding J, et al. Postoperative morbidity and mortality after D1 and D2 resections for gastric cancer: preliminary results of the MRC randomised controlled surgical trial. Lancet 1996;347:995-9.

200 Maruyama K. Surgical treatment and end results of gastric cancer. Tokyo: National Cancer Centre, 1985

201 Hayes N, Karat D, Scott DJ, et al. Radical lymphadenectomy in the management of early gastric cancer. Br J Surg 1996:83:1421-3.

202 Siewert JR, Bottcher K, Roder JD, et al. Prognostic relevance of systematic lymph node dissection in gastric carcinoma. Br J Surg 1993;80:1015-18

203 Siewert JR, Kestlmeier R, Busch R. Benefits of gastric cancer and $p N 0$ pN1 lymph node metastases. Br J Surg 1996;83:1144-7.

204 Maruyama K, Gunven P, Okabayashi K, et al. Lymph node metastases of gastric cancer. General pattern in 1931 patients. Ann Surg 1989;210:596-602

205 Seto Y, Nagawa H, Muto T. Results of extended lymph node dissection for gastric cancer cases with N2 lymph node metastases. Int Surgery 1997;82:257-61.

206 Cuschieri A, Weeden S, Fielding J, et al. Patient survival after D1 and D2 resections for gastric cancer: long term results of the MRC randomised surgical trial. Surgical Co-operative group. Br J Cancer 1999;79:1522-30

207 Bonenkamp JJ, Hermans J, Sasako M, et al. Extended lymph node dissection for gastric cancer. Dutch gastric cancer group. N Engl J Med 1999;340:908-14

208 Griffith JP, Sue-Ling H, Johnston D, et al. Preservation of the spleen improves survival after radical surgery for gastric cancer. Gut 1995; $36: 684-90$.

209 Wanebo HJ, Kennedy BJ, Winchester DP, et al. Role of splenectomy in gastric cancer surgery: an adverse effect of elective splenectomy on long-term survival. J Am Coll Surg 1997; 185:177-84.

210 Okajama K, Isozaki H. Splenectomy for treatment of gastric cancer: Japanese experience. World J Surg 1995;19:537-40.

211 Maruyama K, Sasako M, Kinoshita T, et al. Pancreas-preserving total gastrectomy for proximal gastric cancer. World J Surg 1995;19:532-6.

212 Parikh D, Johnson M, Chagia L, et al. D2 gastrectomy: lessons from a prospective audit of the learning curve. Br J Surg 1996:83:1595-9.

213 McArdle CS, Hole D. An analysis of outcome following gastric cancer surgery. Gl Cancer 1996;1:177-82.

214 Ando N, lizuka T, Kakegawa T, et al. A randomized trial of surgery with and without chemotherapy for localized squamous carcinoma of the thoracic esophagus: the Japan Clinical Oncology Group Study. J Thorac Cardiovasc Surg 1997; 114:205-9.

215 Ando $N$, lizuka T, Ide $\mathrm{H}$, et al. A randomised trial of surgery alone $v$ surgery plus postoperative chemotherapy with cisplatin and 5-fluorouracil for localized squamous carcinoma of the thoracic esophagus: The Japan Clinical Oncology Group Study (JCOG 9204). Proc Am Soc Clin Oncol 1999;18:269a.

216 Kelsen DP, Ginsberg R, Pajak TF, et al. Chemotherapy followed by surgery compared with surgery alone for localized esophageal cancer. N Engl J Med 1998;339:1979-84.

217 Arnott SJ, Duncan W, Gignoux M, et al. Preoperative radiotherapy in esophageal carcinoma: a meta-analysis using individual patient data (Oesophageal Cancer Collaborative Group). Int J Radiat Oncol Biol Phys 1998;41:579-83.

218 Nygaard K, Hagen S, Hansen HS, et al. Pre-operative radiotherapy prolongs survival in operable esophageal carcinoma: a randomized, multicenter study of pre-operative radiotherapy and chemotherapy. The second Scandinavian trial in esophageal cancer. World J Surg 1992; 16:1104-9.

219 Le Prise E, Etienne PL, Meunier B, et al. A randomized study of chemotherapy, radiation therapy, and surgery versus surgery for localized squamous cell carcinoma of the esophagus. Cancer 1994;73:1779-84.

220 Walsh TN, Noonan N, Hollywood D, et al. A comparison of multimoda therapy and surgery for esophageal adenocarcinoma. N Engl J Med 1996:335:462-7

221 Bosset JF, Gignoux M, Triboulet JP, et al. Chemoradiotherapy followed by surgery compared with surgery alone in squamous-cell cancer of the esophagus. N Engl J Med 1997;337:161-7.

222 Urba S, Orringer A, Turrisi R, et al. A randomised trial comparing surgery to preoperative chemoradiation plus surgery in patients with resectable esophageal cancer: updated analysis. Proc Am Soc Clin Oncol 1997; 16:983.

223 Poplin E, Fleming T, Leichman L, et al. Combined therapies for squamous-cell carcinoma of the esophagus, a Southwest Oncology Group Study (SWOG-8037). J Clin Oncol 1987;5:622-8.

224 Forastiere AA, Orringer MB, Perez-Tamayo C, et al. Concurrent chemotherapy and radiation therapy followed by transhiatal esophagectomy for local-regional cancer of the esophagus. J Clin Oncol 1990;8:119-27.

225 Gray JR, Meluch AA, Kalman L, et al. Neoadjuvant paclitaxel/ carboplatin/5-FU/radiation therapy for localised esophageal cancer: Update of a Minnie Pearl Cancer Research Network phase II trial. Proc Am Soc Clin Oncol 1999;18:271a

226 Stahl M, Vanhoefer U, Stuschke M, et al. Pre-operative sequential chemoand radiochemotherapy in locally advanced carcinomas of the lower oesophagus and gastro-oesophageal junction. Eur J Cancer 1998:34:668-73.

227 Hermans J, Bonenkamp JJ, Boon MC, et al. Adjuvant therapy after curative resection for gastric cancer: meta-analysis of randomized trials. $J$ Clin Oncol 1993;11:1441-7.

228 Pignon JP, Ducreux M, Rougier P. Meta-analysis of adjuvant chemotherapy in gastric cancer: a critical reappraisal. J Clin Oncol 1994; 12:877-8.

229 Earle CC, Maroun JA. Adjuvant chemotherapy after curative resection for gastric cancer: revisiting a meta-analysis of randomised trials. Proc Am Soc Clin Oncol 1998;17:263a.

230 Hagiwara A, Takahashi T, Kojima O, et al. Prophylaxis with carbon-adsorbed mitomycin against peritoneal recurrence of gastric cancer. Lancet 1992;339:629-31

231 Rosen HR, Jatzko G, Repse S, et al. Adjuvant intraperitoneal chemotherapy with carbon-adsorbed mitomycin in patients with gastric cancer: results of a randomized multicenter trial of the Austrian Working Group for Surgical Oncology. J Clin Oncol 1998;16:2733-8

232 Kelsen D, Karpeh M, Schwartz G, et al. Neoadjuvant therapy of high-risk gastric cancer: a phase II trial of preoperative FAMTX and postoperative intraperitoneal fluorouracil- cisplatin plus intravenous fluorouracil. J Clin Oncol 1996:14:1818-28.

233 Yu W, Whang I, Suh I, et al. Prospective randomised trial of early postoperative intraperitoneal chemotherapy as an adjuvant to resectable gastric cancer. Ann Surg 1998;228:347-54.

234 Fink U, Schuhmacher C, Stein HJ, et al. Preoperative chemotherapy for stage III-IV gastric carcinoma: feasibility, response and outcome after complete resection. Br J Surg 1995;82:1248-52.

235 Ross PJ, Rao S, Cunningham D. Chemotherapy of oesophago-gastric cancer. Pathol Oncol Res 1998;4:87-95.

236 Wilke $\mathbf{H}$, Preusser P, Fink $U$, et al. Preoperative chemotherapy in locally advanced and nonresectable gastric cancer: a phase II study with etoposide, doxorubicin, and cisplatin. Clin Oncol 1989;7:1318-26.

237 Rougier $\mathbf{P}$, Mahjoubi $M$, Lasser P, et al. Neoadjuvant chemotherapy in locally advanced gastric carcinoma-a phase II trial with combined continuous intravenous 5 -fluorouracil and bolus cisplatinum. Eur J Cancer 1994;30A: 1269-75.

238 Kang YK, Choi DW, Im YH, et al. A phase III randomized comparison of neoadjuvant chemotherapy followed by surgery versus surgery for locally advanced stomach cancer. Proc Am Soc Clin Oncol 1996;15:A503.

239 Songun I, Keizer HJ, Hermans J, et al. Chemotherapy for operable gastric cancer: Results of the Dutch randomised FAMTX trial. Eur J Cancer 1999;35:558-2

240 Macdonald JS, Smalley S, Benedetti J, et al. Postoperative combined radiation and chemotherapy improves disease free survival (DFS) and overall survival (OS) in resected adenocarcinoma of the stomach and GE junction. Results of Intergroup Study INT-01 16 (SWOG 9008). Proc Am Soc Clin Oncol 2000;19:1

241 Loizou LA, Rampton D, Atkinson M, et al. A prospective assessment of quality of life after endoscopic intubation and laser therapy for malignan dysphagia. Cancer 1992;70:386-91.

242 Herskovic A, Martz K, Al Sarraf M, et al. Combined chemotherapy and radiotherapy compared with radiotherapy alone in patients with cancer of the esophagus. N Engl J Med 1992;326:1593-8.

243 Ross P, Cunningham D, Scarffe H, et al. Results of a randomised trial comparing ECF with MCF in advanced oesophagogastric cancer (abstr). Proc Am Soc Clin Oncol 1999:18:272a.

244 Webb A, Cunningham D, Scarffe JH, et al. Randomized trial comparing epirubicin, cisplatin, and fluorouracil versus fluorouracil, doxorubicin, and methotrexate in advanced esophagogastric cancer. J Clin Oncol 1997:15:261-7.

245 Kok TC. Chemotherapy in oesophageal cancer. Cancer Treat Rey 1997;23:65-85. 
246 Andreyev HJ, Norman AR, Cunningham D, et al. Squamous oesophageal cancer can be downstaged using protracted venous infusion of 5-fluorouracil with epirubicin and cisplatin (ECF). Eur J Cance 1995;31a:2209-14

247 Highley MS, Parnis FX, Trotter GA, et al. Combination chemotherapy with epirubicin, cisplatin and 5-fluorouracil for the palliation of advanced gastric and oesophageal adenocarcinoma. Br J Surg 1994;81:1763-5.

248 van der Gaast A, Kok TC, Kerkhofs L, et al. Phase I study of a biweekly schedule of a fixed dose of cisplatin with increasing doses of paclitaxel in patients with advanced oesophageal cancer. Br J Cancer 1999:80:1052-7.

249 Ilson DH, Ajani J, Bhalla K, et al. Phase II trial of paclitaxel, fluorouracil, and cisplatin in patients with advanced carcinoma of the esophagus. J Clin Oncol 1998;16:1826-34.

250 Albertsson $M$, Ewers SB, Widmark $H$, et al Evaluation of the palliative effect of radiotherapy for esophageal-carcinoma. Acta Oncol 1989;28:267-70.

251 Caspers RJL, Welvaart K, Verkes RJ, et al. The effect of diotherapy on dysphagia and survival in patients with esophageal cancer. Radiother Oncol 1988;12:15-23

252 Cwikiel M, Cwikiel W, Albertsson M. Palliation of dysphagia in patients with malignant esophageal strictures. Comparison of results of radiotherapy, chemotherapy and esophageal stent treatment. Acta Oncol 1996;35:75-9.

253 Taal BG, Aleman BM, Koning CC, et al. High dose rate brachytherapy before external beam irradiation in inoperable oesophageal cancer. $\mathrm{Br}$ Cancer 1452:74:1452-7.

254 Pyrhonen S, Kuitunen T, Nyandoto P, et al. Randomised comparison of fluorouracil, epidoxorubicin and methotrexate (FEMTX) plus supportive care with supportive care alone in patients with non-resectable gastric cancer. Br J Cancer 1995;71:587-91.

255 Glimelius B, Ekstrom K, Hoffman K, et al. Randomized comparison between chemotherapy plus best supportive care with best supportive care in advanced gastric cancer. Ann Oncol 1997;8:163-8.

256 Murad AM, Santiago FF, Petroianu A, et al. Modified therapy with 5 -fluorouracil, doxorubicin, and methotrexate in advanced gastric cancer. Cancer 1993;72:37-41.

257 Findlay M, Cunningham D, Norman A, et al. A phase II study in advanced gastro-esophageal cancer using epirubicin and cisplatin in combination with continuous infusion 5-fluorouracil (ECF). Ann Oncol 1994;5:609-16

258 Waters JS, Norman A, Cunningham D, et al. Long-term survival after epirubicin, cisplatin and fluorouracil for gastric cancer: results of a randomized trial. Br J Cancer 1999:80:269-72.

259 Kim YH, Shin SW, Kim BS, et al. Paclitaxel, 5-fluorouracil, and cisplatin combination chemotherapy for the treatment of advanced gastric carcinoma. Cancer 1999;85:295-301.

260 Andre T, Louvet C, Ychou M, et al. Docetaxel-epirubicin as second-line treatment for patients with advanced gastric cancer. Proc Am Soc Clin Oncol 1999; 18:277a.

261 Boku N, Ohtsu A, Shimada Y, et al. Phase II study of a combination of irinotecan and cisplatin against metastatic gastric cancer. J Clin Oncol 1999;17:319-23.

262 Shirao K, Shimada Y, Kondo H, et al. Phase I-II study of irinotecan hydrochloride combined with cisplatin in patients with advanced gastric cancer. J Clin Oncol 1997;15:921-7.

263 Aste H, Munizzi F, Martines H, et al. Esophageal dilation in malignant dysphagia. Cancer 1985:56:2713-15.

264 Moses FM, Peura DA, Wong RK, et al. Palliative dilation of esophageal carcinoma. Gastrointest Endosc 1985:31:61-3.

265 Lundell L, Leth R, Lind T, et al. Palliative endoscopic dilatation in carcinoma of the esophagus and esophagogastric junction. Acta Chir Scand 1989;155:179-84.

266 Payne-James JJ, Spiller RC, Misiewicz JJ, et al. Use of ethanol-induced tumor necrosis to palliate dysphagia in patients with esophagogastric cancer. Gastrointest Endosc 1990;36:43-6.

267 Lee FI, Bellary SV. Ethanol-induced tumor necrosis to palliate esophago-gastric cancer. Gastrointest Endosc 1990;36:418-19.

268 Stanners AJ, Malu AO, Miloszewski KJ. Alcohol injection for palliation of malignant oesophageal disease. Lancet 1993;341:767.

269 Moreira LS, Coelho RC, Sadala RU, et al. The use of ethanol injection under endoscopic control to palliate dysphagia caused by esophagogastric cancer. Endoscopy 1994;26:311-14.

270 Nwokolo CU, Payne-James JJ, Silk DB, et al. Palliation of malignant dysphagia by ethanol induced tumour necrosis. Gut 1994:35:299-303.

271 Chung SC, Leong HT, Choi CY, et al. Palliation of malignant oesophageal obstruction by endoscopic alcohol injection. Endoscopy 1994;26:275-7

272 Guitron A, Adalid R, Huerta F, et al. Palliative treatment of esophageal cancer with transendoscopic injection of alcohol. Rev Gastroenterol Mexico 1996:61:208-11.

273 Loscos JM, Calvo E, Alvarez-Sala JL, et al. Treatment of dysphagia and massive hemorrhage in esophageal carcinoma by ethanol injection. Endoscopy 1993;25:544

274 Fiorini A, Roca E, Capizzano M. Endoscopic recanalization with alcohol in the treatment of dysphagia of neoplastic origin. Acta Gastroenterol Latinoam 1992;22:197-9.

275 Roseveare CD, Patel P, Simmonds N, et al. Metal stents improve dysphagia, nutrition and survival in malignant oesophageal stenosis: a randomized controlled trial comparing modified Gianturco Z-stents with plastic Atkinson tubes. Eur J Gastroenterol Hepatol 1998; 10:653-7.

276 Siersema PD, Hop WC, Dees J, et al. Coated self-expanding metal stents versus latex prostheses for esophagogastric cancer with special reference to prior radiation and chemotherapy: a controlled, prospective study. Gastrointest Endosc 1998;47:113-20.

277 De Palma GD, di Matteo E, Romano G, et al. Plastic prosthesis versus expandable metal stents for palliation of inoperable esophageal thoracic carcinoma: a controlled prospective study. Gastrointest Endosc 1996:43:478-82.

278 Knyrim K, Wagner HJ, Bethge N, et al. A controlled trial of an expansile metal stent for palliation of esophageal obstruction due to inoperable cancer. N Engl J Med 1993;329:1302-7.

279 Bohnacker S, Thonke F, Hinner M, et al. Improved endoscopic stenting for malignant dysphagia using Tygon plastic prostheses. Endoscopy 1998:30:524-31.

280 Atkinson M, Ferguson R, Ogilvie AL. Management of malignant dysphagia by intubation at endoscopy. J R Soc Med 1979;72:894-7.

281 Jones DB, Davies PS, Smith PM. Endoscopic insertion of palliative oesophageal tubes in oesophagogastric neoplasms. Br J Surg 1981;68:197-8.

282 Sagar PM, Gauperaa T, Sue-Ling $\mathrm{H}$, et al. An audit of the treatment of cancer of the oesophagus. Gut 1994;35:941-5.

283 Maydeo AP, Bapaye A, Desai PN, et al. Endoscopic placement of indigenous plastic esophageal endoprostheses-does it still have a role in the era of expandable metallic stents? A prospective Indian study in 265 consecutive patients. Endoscopy 1998;30:532-7.

284 Grund KE, Storek D, Becker HD. Highly flexible self-expanding meshed metal stents for palliation of malignant esophagogastric obstruction. Endoscopy 1995:27:486-94.

285 Ell C, May A, Hahn EG. Gianturco-Z stents in the palliative treatment of malignant esophageal obstruction and esophagotracheal fistulas. Endoscopy 1995;27:495-500

286 Ellul JP, Watkinson A, Khan RJ, et al. Self-expanding metal stents for the palliation of dysphagia due to inoperable oesophageal carcinoma. $\mathrm{Br} J$ Surg 1995;82:1678-81.

287 Song HY, Choi KC, Kwon HC, et al. Esophageal strictures: treatment with a new design of modified Gianturco stent. Work in progress. Radiology 1992;184:729-34

288 Wu WC, Katon RM, Saxon RR, et al. Silicone-covered self-expanding metallic stents for the palliation of malignant esophageal obstruction and esophagorespiratory fistulas: experience in 32 patients and a review of the literature. Gastrointest Endosc 1994;40:22-33.

289 Vermeiiden JR, Bartelsman JF, Fockens $\mathrm{P}$, et al. Self-expanding metal stents for palliation of esophagocardial malignancies. Gastrointest Endosc 1995:41:58-63.

290 Neuhaus H, Hoffmann W, Dittler HJ, et al. Implantation of self-expanding esophageal metal stents for palliation of malignant dysphagia. Endoscopy 1992;24:405-10.

291 Segalin A, Bonavina L, Carazzone A, et al. Improving results of esophageal stenting: a study on 160 consecutive unselected patients. Endoscopy 1997;29:701-9.

292 Kozarek RA, Raltz S, Marcon N, et al. Use of the $25 \mathrm{~mm}$ flanged esophageal $Z$ stent for malignant dysphagia: a prospective multicenter trial. Gastrointest Endosc 1997:46:156-60.

293 Birch JF, White SA, Berry DP, et al. A cost-benefit comparison of self-expanding metal stents and Atkinson tubes for the palliation of obstructing esophageal tumors. Dis Esophagus 1998;11:172-6.

294 Sargeant IR, Thorpe S, Bown SG. Cuffed esophageal prosthesis: a useful device in desperate situations in esophageal malignancy. Gastrointest Endosc 1992;38:669-75.

295 Han YM, Song HY, Lee JM, et al. Esophagorespiratory fistulae due to esophageal carcinoma: palliation with a covered Gianturco stent. Radiology 1996;199:65-70.

296 May A, Ell C. Palliative treatment of malignant esophagorespiratory fistulas with Gianturco-Z stents. A prospective clinical trial and review of the literature on covered metal stents. Am J Gastroenterol 1998;93:532-5

297 Nelson DB, Axelrad AM, Fleischer DE, et al. Silicone-covered Wallstent prototypes for palliation of malignant esophageal obstruction and digestive-respiratory fistulas. Gastrointest Endosc 1997;45:31-7.

298 Do YS, Song HY, Lee BH, et al. Esophagorespiratory fistula associated with esophageal cancer: treatment with a Gianturco stent tube. Radiology 1993;187:673-7.

299 Weigert N, Neuhaus H, Rosch T, et al. Treatment of esophagorespiratory fistulas with silicone-coated self-expanding metal stents. Gastrointest Endosc 1995;41:490-6.

300 Kozarek RA, Raltz S, Brugge WR, et al. Prospective multicenter trial of esophageal Z-stent placement for malignant dysphagia and tracheoesophageal fistula (published erratum appears in Gastrointest Endosc 1996;44:764). Gastrointest Endosc 1996;44:562-7

301 Fiorini AB, Goldin E, Valero JL, et al. Expandable metal coil stent for treatment of broncho-esophageal fistula. Gastrointest Endosc 1995:42:81-3.

302 Watkinson A, Ellul J, Entwisle K, et al. Plastic-covered metallic endoprostheses in the management of oesophageal perforation in patients with oesophageal carcinoma. Clin Radiol 1995;50:304-9.

303 Oliver SE, Robertson CS, Logan RFA, et al. What does radiotherapy add to survival over endoscopic intubation alone in inoperable squamous-cell esophageal cancer. Gut 1990;31:750-2.

304 Bethge N, Sommer A, von Kleist D, et al. A prospective trial of self-expanding metal stents in the palliation of malignant esophagea obstruction after failure of primary curative therapy. Gastrointest Endosc 1996;44:283-6.

305 Kinsman KJ, DeGregorio BT, Katon RM, et al. Prior radiation and chemotherapy increase the risk of life-threatening complications after 
insertion of metallic stents for esophagogastric malignancy. Gastrointest Endosc 1996;43:196-203.

306 Nemoto K, Takai Y, Ogawa Y, et al. Fatal hemorrhage in irradiated esophageal cancer patients. Acta Oncol 1998;37:259-62

307 Uno Y, Obara K, Kanazawa K, et al. Stent implantation for malignant pyloric stenosis. Gastrointest Endosc 1997;46:552-5.

308 Loizou LA, Grigg D, Atkinson M, et al. A prospective comparison of laser therapy and intubation in endoscopic palliation for malignant dysphagia. Gastroenterology 1991;100:1303-10.

309 Buset M, des Marez B, Batze M, et al. Palliative endoscopic management of obstructive oesophagogastric cancer: laser or prosthesis? Gastrointest Endosc 1987;33:357-61

310 Alderson D, Wright PD. Laser recanalization versus endoscopic intubation in the palliation of malignant dysphagia. BrJ Surg 1990;77:1151-3.

311 Carter R, Smith JS, Anderson JR. Laser recanalization versus endoscopic intubation in the palliation of malignant dysphagia: a randomized prospective study. Br J Surg 1992;79:1 167-70.

312 Bourke MJ, Hope RL, Chu G, et al. Laser palliation of inoperable malignant dysphagia: initial and at death. Gastrointest Endosc 1996;43:29-32.

313 Hurley JF, Cade RJ. Laser photocoagulation in the treatment of malignant dysphagia. Aus NZ J Surg 1997;67:800-3.

314 Maciel J, Barbosa J, Leal AS. Nd-YAG laser as a palliative treatment for malignant dysphagia. Eur J Surg Oncol 1996;22:69-73.

315 Mitty RD, Cave DR, Birkett DH. One-stage retrograde approach to $\mathrm{Nd}$ :YAG laser palliation of esophageal carcinoma. Endoscopy 1996;28:350-5.

316 Krasner N, Barr H. Palliative laser therapy for malignant dysphagia. Gut 1987;28:792-8.

317 Gossner L, Ell C. Malignant strictures. Thermal treatment. Gastrointest Endosc Clin North Am 1998;8:493-501.

318 Gevers AM, Macken E, Hiele M, et al. A comparison of laser therapy, plastic stents, and expandable metal stents for palliation of malignant dysphagia in patients without a fistula. Gastrointest Endosc 1998;48:383-8.

319 Barr H, Krasner N, Raouf A, et al. Prospective randomised trial of laser therapy only and laser therapy followed by endoscopic intubation for the palliation of malignant dysphagia. Gut 1990;31:252-8.

320 Sargeant IR, Tobias JS, Blackman G, et al. Radiotherapy enhances laser palliation of malignant dysphagia: a randomised study. Gut 1997;40:362-9.

321 Bader M, Dittler HJ, Ultsch B, et al. Palliative treatment of malignant stenoses of the upper gastrointestinal-tract using a combination of lase and afterloading therapy. Endoscopy 1986;18(suppl 1):27-31.
322 Tan CC, Freeman JG, Holmes GK, et al. Laser therapy combined with brachytherapy for the palliation of malignant dysphagia. Singapore Med J 1998;39:202-7.

323 Shmueli E, Srivastava E, Dawes PJ, et al. Combination of laser treatment and intraluminal radiotherapy for malignant dysphagia. Gut 1996;38:803-5

324 Spencer GM, Thorpe SM, Sargeant IR, et al. Laser and brachytherapy in the palliation of adenocarcinoma of the oesophagus and cardia. Gut 1996;39:726-31.

325 Ludwig D, Dehne A, Burmester E, et al. Prognostic factors in patients with malignant esophageal stenosis and palliative treatment with self-expanding mesh stents. Gastrointest Endosc 1997;45:AB73.

326 Sawant D, Moghissi K. Management of unresectable oesopahgeal cancer. Eur J Cardiothorac Surg 1994;8:113-17.

327 Simsek H, Öksuzoglu G, Akhan O. Endoscopic Nd:YAG laser therapy for esophageal Wallstent occlusion due to tumor ingrowth. Endoscopy 1996;28:28

328 Lightdale CJ, Heier SK, Marcon NE, et al. Photodynamic therapy with porfimer sodium versus thermal ablation therapy with $\mathrm{Nd}$ :YAG laser for palliation of esophageal cancer: a multicenter randomized trial. Gastrointest Endosc 1995;42:507-12.

329 Heier SK, Rothman KA, Heier LM, et al. Photodynamic therapy for obstructing esophageal cancer-light dosimetry and randomized comparison with Nd-YAG laser therapy. Gastroenterology 1995; 109:63-72.

330 Waghorn A, Thompson J, McKee M. Routine surgical follow-up: do surgeons agree? BM 1995;311:1344-5.

331 Hulton NR, Hargreaves AW. Is long term follow-up of all colorectal patients necessary? J R Coll Surg Edin 1989;34:21-4.

332 Huguier M, Houry S, Lacaine F. Is the follow-up of patients operated upon for gastric carcinoma of benefit to the patient? Hepatogastroenterology 1992;39:14-16.

333 Dewar J. Follow-up in breast cancer-a suitable case for reappraisal. BM 1995;310:685-6.

334 Cochrane JPS, Williams JT, Faber RG, et al. Value of outpatient follow-up after curative surgery for carcinoma of the large bowel. BM 1980;280:593-5.

335 Department of Health and Welsh Office. A policy framework for commissioning cancer services. A report by the expert advisory group on cancer to the chief medical officers of England and Wales. DoH and Welsh Office, 1995

336 Kiebert GM, Welvaart K, Kievit J. Psychological effects of routine follow-up on cancer patients after surgery. Eur J Surg 1993;159:601-7. 
Notes

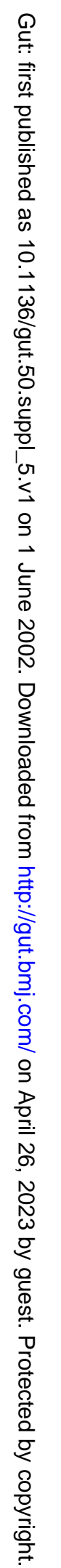

